\title{
La cláusula resolutoria como manifestación de la facultad de resolver el contrato. Problemas en torno a su eficacia en el Código Civil chileno*
}

\author{
The Termination Clause as an Expression of Termination Right. Problems in Respect of its Effectiveness in the \\ Chilean Civil Law
}

\author{
ÁLVARO VIDAL-OLIVARES ${ }^{\text {a }}$ \\ Pontificia Universidad Católica de Valparaiso, Chile \\ Alvaro.vidal@pucv.cl \\ ORCID: http://orcid.org/0000-0001-5362-9310
}

\author{
DOI: https://doi.org/10.11144/Javeriana.vj138.crmf \\ Redalyc: http://www.redalyc.org/articulo.oa?id=82559799013 \\ Fecha de recepción: 30 Septiembre 2018 \\ Fecha de aprobación: 25 Octubre 2018 \\ Fecha de publicación: 30 Mayo 2019
}

\begin{abstract}
Resumen:
El artículo 1489 del Código Civil chileno prevé una resolución judicial por incumplimiento de contrato bilateral; sin embargo, este remedio no ofrece al acreedor una protección suficiente, al imponerle la carga de iniciar un juicio declarativo, cuyo resultado — la declaración de resolución del contrato- depende, en último término, de la calificación que hará el juez del incumplimiento en que se fundó la demanda. Por este orden de consideraciones, resulta conveniente la inclusión de cláusulas resolutorias que, junto con definir los incumplimientos esenciales, reconozcan al acreedor la facultad de resolver el contrato por comunicación y con efecto extrajudicial. Sin embargo, como el Código Civil chileno no dispone sobre el particular, en la práctica contractual los pactos de esta especie producen una serie de problemas en torno a su validez y eficacia. El presente trabajo, además de mostrar estos problemas, ofrece soluciones, apoyándose principalmente en las sentencias de los Tribunales superiores de justicia de Chile.
\end{abstract}

Palabras clave: Resolución, libertad contractual, incumplimiento de contrato.

\section{Abstract:}

Article 1489 of the Chilean Civil Code provides for a judicial termination for breach of contract. However, this remedy does not offer the creditor sufficient protection, by imposing the burden of initiating a declaratory trial, whose result - the termination of the contract- depends, in the end, of the qualification that the judge will make of the nonperformance in which the claim was based. It is in this order of considerations that it is convenient to include termination clauses that, together with defining the essential breaches, recognize the creditor the right to terminate the contract by communication and with extrajudicial effect. However, as the Chilean Civil Code does not provide for this, in contractual practice this agreement produces a series of problems regarding its validity and effectiveness. The present work, together with showing these problems, offers solutions, mainly based on the judgments of the Superior Courts of Justice of Chile.

Keywords: Termination, Freedom of contract, Breach of contract.

\section{Introducción}

El artículo 1489 del Código Civil chileno prevé la resolución judicial por inejecución de un contrato bilateral por uno de los contratantes. Si bien en abstracto la solución que ofrece el precepto confiere una adecuada protección al acreedor afectado, lo cierto es que, en la práctica, ella suscita muchos inconvenientes no solo para el acreedor, sino para el normal desenvolvimiento del tráfico. La resolución judicial asigna la carga de accionar al acreedor, pues aun iniciando el respectivo juicio ordinario o arbitral, según sea el caso, su posición es incierta en lo que concierne a los resultados, dado que el juez puede calificar o no de esencial el incumplimiento. Este orden de consideraciones, en buena medida, justifica la necesidad del estudio de las cláusulas resolutorias como manifestación de la facultad de resolver el contrato que las partes, en ejercicio de

Notas de autor:

${ }^{a}$ Autor de correspondencia. Correo electrónico: Alvaro.vidal@pucv.cl 
su libertad contractual, incorporan a sus contratos. Tales cláusulas pueden tener por objeto desde la forma de ejercicio de la facultad, hasta cómo operará la resolución, pasando por la definición de los incumplimientos con trascendencia resolutoria y los efectos del ejercicio de este remedio.

La inclusión de esta especie de cláusulas desplaza, en todo o parte — según la extensión del acuerdo de los contratantes - la norma dispositiva o supletoria de la voluntad del artículo 1489 del Código Civil. Un elemento accidental se impone sobre aquel de la naturaleza (artículo 1444 del Código Civil chileno).

El punto es que la cláusula resolutoria no ha llamado especialmente la atención a nuestra doctrina, salvo el caso del trabajo de CARLOS PIZARRO-WILSON ${ }^{1}$, quien, si bien le reconoce autonomía como dispositivo para la protección del acreedor, entiende que convive con el pacto comisorio calificado ${ }^{2}$, fruto de la generalización de las disposiciones de la compraventa para el incumplimiento de la obligación de pagar el precio. Sin embargo, en general, quienes se ocupan de la estipulación de resolución extrajudicial lo hacen exclusivamente desde la disciplina del Código Civil del pacto comisorio calificado, aproximación que ofrece más problemas que soluciones ${ }^{3}$.

Esta clase de cláusulas originan una serie de problemas, tanto referidos a su validez, como a su eficacia, lo cual obliga al intérprete a enfrentar dos principios rectores de la contratación: la fuerza obligatoria del contrato - el respeto de lo querido por las partes - y la buena fe objetiva, es decir, la necesidad de consideración del otro contratante. A partir de la presentación de estos problemas, examinaremos los aspectos fundamentales a considerar cuando se trate de construir una cláusula resolutoria, para anticiparnos y prever, de esta forma, los eventuales conflictos cuya ejecución puede producir entre las partes.

Con este propósito, el presente trabajo consta de tres partes y termina con unas conclusiones. La primera trata de la modulación convencional de los remedios contractuales y de la justificación de incorporar una cláusula resolutoria; la segunda, de la disciplina de las cláusulas resolutorias y la presentación de los problemas de validez y eficacia a que ellas pueden dar lugar en la práctica; la tercera, de una mayor extensión, se ocupa particularmente de tales problemas. El trabajo termina con unas conclusiones.

\section{Desde la modulación convencional de los remedios contractuales a la cláusula resolutoria}

\section{Libertad de pacto y la norma dispositiva sobre efectos del incumplimiento}

Nos situamos en el ámbito del incumplimiento contractual y de la libertad de las partes para configurar los remedios a tal incumplimiento.

Asumiendo que el contrato es un dispositivo que prevé, tanto para el cumplimiento como para su incumplimiento ${ }^{4}$, las partes pueden, entre otras cosas, incorporar pactos o cláusulas que fijen, en todo o parte, la disciplina de los remedios del acreedor para el evento del incumplimiento. Si ellas guardan silencio, cobrará todo su imperio la norma dispositiva - que suple su voluntad, integrando el contenido de la regla contractual -, no como norma legal, sino como integrante de tal contenido. Aplica en toda su dimensión el artículo 1545 del Código Civil.

Las disposiciones que reglan sobre los efectos del incumplimiento constituyen elementos de la naturaleza del contrato, de acuerdo con el artículo 1444 del Código Civil: sean comunes a todo contrato, como es el caso, entre otros, de los artículos 1489, 1547, 1556 y 1558, todos del Código Civil; o particulares para un tipo contractual, como en la compraventa los artículos 1826 y 1873 del Código Civil. Elementos que los contratantes - por ser de la naturaleza haciendo uso de su libertad contractual- pueden modificar o excluir (siempre con algunos límites), al incorporar pactos accesorios (elementos accidentales), para modular, de esta forma — según lo estimen conveniente a sus intereses-, el incumplimiento y sus efectos ${ }^{5}$. De este modo, se 
conectan los elementos de la naturaleza con los accidentales, entendiendo que estos últimos son expresión de la común intención de los contratantes (artículo 1560 del Código Civil. Afirmación válida para contratos libremente discutidos, no así para aquellos por adhesión respecto de los cuales la ley especial Ley 19.496- o el derecho común prevé los mecanismos tendientes a la corrección de aquellas cláusulas que puedan calificarse de abusivas, a través de su declaración de nulidad ${ }^{6}$.

Esta libertad de pacto tiene reconocimiento expreso, en especial para la compraventa, en el artículo 1887 del Código Civil, al disponer que "Pueden agregarse al contrato de venta cualesquiera otros pactos accesorios lícitos; y se regirán por las reglas generales de los contratos" y se reitera con relación a la indemnización de daos en los incisos finales de los artículos 1547 y 1558 del mismo código.

Si estamos de acuerdo en generalizar estas normas, en ellas encontramos un reconocimiento a la libertad contractual (de configuración interna, cuyo ejercicio queda sometido a los límites impuestos por las reglas generales de los contratos: la ley, el orden público y las buenas costumbres ${ }^{7}$, a las que se suman, en la opinión de MARIO E. CLEMENTE-MEORO, la buena fe y la lealtad negocial ${ }^{8}$.

¿Qué conclusión podemos extraer hasta aquí? Que la disciplina legal de los remedios contractuales (elementos de la naturaleza integran la regla contractual, mientras ella no sea desplazada, total o parcialmente, por estipulaciones expresas lícitas. El incumplimiento contractual se someterá a tales normas legales y/o estipulaciones de las partes. Quiere decir que si las partes nada dicen, aplica la norma dispositiva, en lo que aquí interesa, el artículo 1489 del Código Civil. En cambio, si en ejercicio de su libertad contractual modifican o alteran su contenido, prevalece el pacto. Sobre el particular, PIZARRO-WILSON, a propósito de las cláusulas resolutorias como concreción convencional de la resolución por inejecución, sostiene:

Existiendo claridad sobre la calificación de la condición resolutoria tácita como elemento de la naturaleza, pudiendo excluirse por las partes, no cabe duda de que puedan modificarse sus efectos o características a partir del acuerdo de las partes. No es más que una manifestación de la libertad contractual, pudiendo incluso renunciarse (...) conforme al artículo 12 del Código Civil $^{9}$.

\section{Y, en fin, BEATRIZ GREGORACI explica:}

Toda norma de carácter dispositivo proporciona a las partes una regulación estándar, de carácter supletorio, liberándolas de tener que descender a regular detalladamente su relación o un aspecto concreto de la misma, en caso de que no quieran hacerlo. Pero si las partes, en uso de su autonomía privada, esto es, en la negociación del contrato, deciden regular su relación contractual de un modo distinto, por ser el que más conviene a sus intereses y a las circunstancias en que se celebra el contrato, la norma dispositiva está siendo desplazada por el pacto y carece de sentido invocar su aplicación ${ }^{10}$.

\section{La facultad resolutoria del artículo 1489 del Código Civil y su necesidad de modulación convencional}

Al examinar la regla del artículo 1489 del Código Civil y la facultad de resolver el contrato que ella confiere al acreedor, podemos detectar una serie de inconvenientes que invitan a las partes a modular convencionalmente el remedio resolutorio de aquella forma que les parezca más acorde a sus intereses. En primer lugar, al ser la facultad resolutoria un derecho potestativo o de configuración jurídica, que necesariamente requiere de la intervención judicial ${ }^{11}$, si el acreedor se inclina por la resolución del contrato, deberá iniciar un juicio ordinario o arbitral, de haberse incorporado al contrato un convenio arbitral. Como sea, esa parte deberá iniciar un juicio para liberarse del contrato y de su deudor incumplidor. Seguidamente, como si fuera poco, los resultados de tal juicio son siempre inciertos, al depender la calificación del carácter esencial o no del incumplimiento en que se fundó la demanda de resolución, del juez que conozca y falle el asunto. Estas consideraciones, entre otras, nos llevan a concluir que el régimen de la resolución judicial no confiere una protección adecuada al acreedor, siendo suficientes para justificar la regulación convencional de la resolución 
del contrato, a través de la incorporación una cláusula accidental por la cual los contratantes regulen la facultad de resolver el contrato, superando, de esta forma, los reseñados inconvenientes. Las partes acuerdan una resolución convencional que, por regla general, operará por comunicación y extrajudicialmente. En esta última hipótesis, la carga de accionar se invierte, pues pasa del acreedor (resolución judicial) al deudor (resolución convencional) ${ }^{12}$, con lo cual alcanza un modelo de resolución más eficiente no solo para el acreedor, sino también para el correcto desenvolvimiento del mercado.

\section{La disciplina de las cláusulas resolutorias en el derecho civil}

comunicación y el efecto extrajudicial ${ }^{13}$. Así, el artículo 98 de los Principios Latinoamericanos de Derecho de Contratos (en adelante, PLDC) dispone:

La resolución opera mediante comunicación escrita a la otra parte y produce efectos desde su recepción ${ }^{14}$.

Esta sintética disposición da cuenta de una regla bastante más funcional al interés del acreedor que la del artículo 1489 del Código Civil, que le permite resolver extrajudicialmente, mediante una comunicación escrita. La resolución, desde luego, deberá fundarse en un incumplimiento esencial conforme con el artículo $87 \mathrm{PLDC}^{15}$. La resolución opera desde la recepción de la comunicación, razón por la cual al deudor pertenece la carga de poner en movimiento el aparato judicial, si entiende que la resolución es improcedente. La carga de accionar se invierte.

Entonces, en sistemas como el del Código Civil chileno, las cláusulas resolutorias representan el mecanismo que permite, por un lado, superar los inconvenientes de una resolución judicial, a los que hemos hecho referencia y, por otro, dotar a los contratantes de una resolución que opere bajo tales términos — por comunicación y extrajudicialmente-, sin perjuicio de otros contenidos que las partes estimen pertinentes, en especial, la definición de los incumplimientos esenciales.

La interrogante que surge es ¿cuál es la disciplina que gobierna este tipo de cláusulas? Bien sabemos que el Código Civil regula el "pacto comisorio" ${ }^{16}$ en la compraventa, pacto en virtud del cual las partes estipulan que, si el comprador no paga el precio, el contrato se resuelve, sin perjuicio de la opción del vendedor de conservar el contrato y demandar el cumplimiento de la obligación (art. 1877 y 1879 Código Civil). Y, también que este pacto comisorio puede ser de dos especies: simple o calificado. Por este último, las partes acuerdan la resolución ipso facto; no obstante, ella igualmente requiere de demanda judicial, al punto de que el comprador puede hacer subsistir el contrato si paga el precio dentro de las 24 horas siguientes a su notificación. Si no lo hace, opera la resolución y la sentencia judicial se limitará a constatarla.

Cabe resaltar que el pacto comisorio, simple o calificado, no priva al vendedor de la opción prevista en el artículo 1873 del Código Civil; por consiguiente, la diferencia entre el pacto comisorio simple y el calificado reside en que el primero no hace distinción con la regla general del artículo 1489 y la particular del citado artículo 1873, tanto es así que se afirma que es una condición resolutoria tácita expresada ${ }^{17}$. En cambio, en el pacto comisorio calificado, a pesar de lo convenido por las partes, si el vendedor opta por resolver la compraventa, igualmente deberá demandar, destacando dos particularidades: a) para la procedencia de la resolución es suficiente el no pago del precio; y b) a pesar de lo anterior, el efecto resolutorio operará automáticamente solo si el comprador no paga dentro de las 24 horas siguientes a la notificación de la demanda, no obstante la necesidad que la respectiva sentencia judicial así lo constate.

Quiere decir, entonces, que nuestro Código Civil ni reconoce, ni menos regula la cláusula de resolución de pleno derecho y de carácter extrajudicial.

Por estas consideraciones, preferimos prescindir de la discusión acerca de la aplicación extensiva del pacto comisorio a otras obligaciones nacidas de la misma compraventa, como asimismo a contratos bilaterales 
diversos ${ }^{18}$. Luego de examinar la doctrina chilena, nuestra firme impresión es que la construcción dogmática de la cláusula resolutoria desde la disciplina del pacto comisorio de la compraventa resulta ser un camino pedregoso que ofrece más problemas que soluciones ${ }^{19}$.

Sencillamente, asumimos que los contratantes, en todo contrato bilateral, haciendo uso de su libertad de configuración interna, están facultados para incorporar cláusulas de resolución extrajudicial o "resolutorias", cuyos efectos quedan sometidos a las reglas generales de todo acto y contrato (artículo 1887 Código Civil ${ }^{20}$.

A diferencia de nuestro Código Civil y de otros, en el derecho comparado y moderno derecho de los contratos sí se dan reglas para las cláusulas resolutorias. Así, en el nuevo Código Civil y de Comercio argentino, se regula la cláusula resolutoria —expresa (art. 1086y tácita (art. $1087^{21}$ —, y se establece como condición para la resolución que el incumplimiento en que se funde sea esencial (artículo 1084. Y el artículo 1086 dispone:

Cláusula resolutoria expresa. Las partes pueden pactar expresamente que la resolución se produzca en caso de incumplimientos genéricos o específicos debidamente identificados. En este supuesto, la resolución surte efectos a partir de que la parte interesada comunica a la incumplidora en forma fehaciente su voluntad de resolver ${ }^{22}$.

Entonces, de la disposición transcrita se sigue que la cláusula debe identificar los incumplimientos (la tipificación debe ser específica) y que la resolución surtirá sus efectos desde cuando el acreedor comunica al deudor en forma fehaciente su voluntad de resolver. Según la disposición, la resolución opera extrajudicialmente por comunicación ${ }^{23}$.

El Código Civil italiano, en su artículo 1456 Clausola risolutiva espressa prescribe:

I contraenti possono convenire espressamente che il contratto si risolva nel caso che una determinata obbligazione non sia adempiuta secondo le modalità stabilite. In questo caso, la risoluzione si verifica di diritto quando la parte interessata dichiara all' altra che intende valersi della clausola risolutiva ${ }^{24}$.

$\mathrm{Al}$ igual que el Código argentino, el italiano requiere un pacto en que las partes tipifiquen el -o losincumplimiento(s) de determinadas obligaciones y de una comunicación de la parte afectada a la otra, para que la resolución opere extrajudicialmente.

Seguidamente, el artículo 1430 del Código Civil peruano dispone sobre la "condición resolutoria" que corresponde a lo que nosotros hemos calificado como cláusula resolutoria. El precepto prescribe:

Puede convenirse expresamente que el contrato se resuelva cuando una de las partes no cumple determinada prestación a su cargo, establecida con toda precisión. La resolución se produce de pleno derecho cuando la parte interesada comunica a la otra que quiere valerse de la cláusula resolutoria.

Por su parte, el artículo 474 del Código Civil de Brasil —al pronunciarse sobre la cláusula resolutoria一, al igual que el Código Civil y Comercial argentino, distingue la expresa de la tácita. El precepto tiene el siguiente tenor:

A cláusula resolutiva expressa opera de pleno direito; a tácita depende de interpelação judicial.

Esta disposición, a diferencia de las tres anteriores, es incompleta al guardar silencio acerca de los contenidos de las cláusulas resolutorias. No contiene ni la exigencia de la especificación de los incumplimientos u obligaciones, ni la necesidad de comunicación para que se produzca el efecto resolutorio. Se limita a reconocer a los contratantes la libertad de incorporar cláusulas resolutorias expresas cuyos efectos se producirán de pleno derecho. Al no distinguir, la resolución podrá operar por comunicación o de forma automática por el mero incumplimiento.

En lo que concierne al derecho francés, la reciente reforma al Código Civil de ese país introdujo la siguiente disposición en su artículo 1225: 
"La cláusula resolutoria designará los compromisos cuyo incumplimiento conllevará la resolución del contrato. «La resolución estará supeditada a un requerimiento infructuoso, salvo que se hubiere convenido que resultaría del mero hecho del incumplimiento. El requerimiento tan solo tendrá efecto si hace constar de forma manifiesta la cláusula resolutoria”.

Si nos detenemos en la regla del nuevo orden contractual francés, hemos de advertir que en ella se recoge la exigencia de la especificidad de la cláusula en orden a que las partes deben designar la obligación cuyo incumplimiento pone a disposición del acreedor la facultad de resolver. Además, otro aspecto al que debemos prestar atención es que se incorpora, como regla supletoria, que, si las partes nada acuerdan, el acreedor deberá requerir al deudor para que subsane el incumplimiento y, solo si es infructuoso, procede la resolución contractual. $Y$ es una regla supletoria porque aplicará a falta de pacto en otro sentido. Finalmente, la norma francesa precisa cómo opera la resolución, por comunicación y desde su recepción.

Finalmente, los PLDC prevén en su artículo 101 (Cláusulas resolutorias):

(1) Las partes pueden incorporar al contrato cláusulas que confieran al acreedor la facultad de resolverlo. (2) La cláusula debe indicar las obligaciones cuyo incumplimiento conlleva resolución. (3) Estas cláusulas no privan al acreedor de la posibilidad de optar por cualquiera de los otros medios de tutela.

Cabe advertir que, al igual que la norma del Código Civil brasileño, la disposición de los PLDC es incompleta; y lo es porque no define la forma de ejercicio de la facultad resolutoria, ni cómo opera la resolución, a diferencia de los otros dos ordenamientos de referencia ${ }^{25}$. Parece que la disposición — tan amplia, como la brasileña - permitiría no solo la inclusión de cláusulas de resolución por comunicación, sino también de pleno derecho o automática.

De las disposiciones examinadas, parece que tres serían los aspectos caracterizadores de una cláusula resolutoria, a saber: primero, que las cláusulas resolutorias son pactos que las partes incorporan al contrato y que confieren al acreedor la facultad de resolverlo por comunicación; segundo, que estas cláusulas deben especificar los incumplimientos resolutorios o las obligaciones cuyo incumplimiento activará la facultad de resolver el contrato; y tercero, que hecha la comunicación y recibida esta por el deudor incumplidor, la resolución opera extrajudicialmente y de pleno derecho.

\section{La cláusula resolutoria y sus problemas en torno a su validez y eficacia}

Ante todo, la primera pregunta que hemos de formularnos es ¿qué debemos entender por cláusula resolutoria?

De lo hasta aquí expresado y de la regulación de estas cláusulas en los tres instrumentos normativos del apartado anterior, podemos afirmar que la cláusula resolutoria es aquella que confiere trascendencia resolutoria a específicos incumplimientos u obligaciones nacidas de un contrato bilateral, y les otorga a las partes la facultad de resolverlo extrajudicialmente mediante comunicación ${ }^{26}$. Entonces, los rasgos característicos de una genuina cláusula resolutoria son ${ }^{27}:$ (1) reconocimiento de la facultad resolutoria, (2) definición de los incumplimientos esenciales ${ }^{28}$; y (3) que la resolución opere por comunicación y extrajudicialmente ${ }^{29}$.

Este trabajo destacar, y es la razón que lo justifica, que, ante la ausencia de una disciplina en el Código Civil que disponga sobre esta especie de cláusulas y su empleo en la práctica, ellas dan lugar a una serie de problemas en torno a su validez y eficacia, entre los que resaltan: (1) el primero que refiere a su validez; (2) el segundo, a la eficacia de las cláusulas de resolución automática o de pleno derecho; (3) el tercero, a la definición de los incumplimientos resolutorios y la necesidad de especificidad; y (4), en fin, a si es compatible o no la resolución convencional (cláusula resolutoria) o con la resolución judicial (artículo 1489 Código Civil). En lo que queda del trabajo, nos detendremos en cada uno de estos problemas. 


\title{
Validez de las cláusulas resolutorias
}

Qué duda cabe de que, pese a la falta de una regulación particular en el Código Civil, las partes, en ejercicio de su libertad contractual, pueden disponer de su artículo 1489, modificándolo e incluso renunciando a la facultad resolutoria ${ }^{30}$. En lo que concierne a los pactos modificatorios, sabemos que son lícitos en la medida en que las partes observen las reglas generales sobre validez de los actos y contratos. Siendo así, hemos de coincidir en que las partes son titulares de la facultad de incorporar al contrato cláusulas resolutorias y que, si ellas cumplen los requisitos del artículo 1445 del Código Civil, son plenamente válidas y eficaces, con lo cual desplaza total o parcialmente la regla del citado artículo 1489.

Entonces, el presupuesto de las cláusulas resolutorias se halla, primero, en la naturaleza dispositiva de este último artículo y, seguidamente, en la facultad o libertad de las partes de modificarla ${ }^{31}$.

La Corte Suprema reconociendo que las partes tienen libertad para desplazar la norma dispositiva siempre que el pacto sea lícito, expresa que:

Judicializar el pacto comisorio calificado repugna a la esencia de este pacto, afectando con ello el principio de la libertad contractual, toda vez que si las partes acordaron que el incumplimiento acarrea la resolución de pleno derecho debe respetarse la voluntad expresada en el contrato, puesto que si hubieren querido otra cosa lo habrían especificado, salvo en aquellos casos en que exista un interés superior comprometido, o se afecte el orden público, la moral o las buenas costumbres, lo que no ocurre en la especie $^{32}$.

De la sentencia se extrae que la validez de la cláusula resolutoria solo se verá afectada si existe alguna norma limitativa de la libertad contractual, indisponible por voluntad de los contratantes.

En este apartado me referiré a la validez de la cláusula resolutoria por no pago de la renta del contrato de arrendamiento regido por la Ley $18.101^{33}$. Sobre este punto, identificamos dos posiciones jurisprudenciales.

La primera, que resta validez a la cláusula, al entender que las normas de los artículos 1977 del Código Civil y del artículo 10 de la Ley 18.101 son imperativas e indisponibles, de modo que, si el arrendatario no paga la renta, estas disposiciones fijarían el camino al arrendador para terminar el contrato (la forma en que opera la resolución), asumiendo que el último precepto reconoce un derecho a favor del arrendatario, que conforme con el artículo 19 de la misma ley, sería irrenunciable. Así, en la sentencia de la Corte de Apelaciones de Santiago de 6 de noviembre de $2015^{34}$ se lee:

\begin{abstract}
Quinto: Por lo tanto, el incumplimiento de la obligación de pagar la renta tiene una normativa particular, en el sentido que el arrendador solo está facultado para poner término al contrato una vez que el arrendatario sea constituido en mora por un período entero y únicamente después de haberse efectuado las dos reconvenciones judiciales que manda la ley. Ahora, no puede descartarse a priori que tal regla pueda alterarse a través de la ley del contrato o, que es lo mismo, por medio de un acuerdo de las partes, en ejercicio de la autonomía de la voluntad. Empero, para ese efecto sería preciso asumir que las normas aludidas integran aquello que puede estar sujeto a la libre disposición de los contratantes. Sin embargo, el artículo 19 de la ley $\mathrm{N}^{\circ} 18.101$ establece de modo inequívoco que \#Son irrenunciables los derechos que esta ley concede a los arrendatarios\#. De ahí que sea dable concluir que se trata de normas de orden público; que, en el extremo que se examina, el arrendamiento es un contrato dirigido y que, por ende, tales disposiciones legales no están sujetas a la libre disponibilidad de los contratantes.
\end{abstract}

No obstante, en sentencia de 11 de mayo de $2016^{35}$, yendo en la dirección contraria, la Corte Suprema se pronuncia reconociendo plena validez y eficacia al pacto comisorio calificado ${ }^{36}$, al expresar, en lo que nos interesa:

El artículo 1977 no tiene sin embargo la forma de una disposición limitativa de la autonomía contractual. Por el contrario, ella concede un derecho al arrendador y regula la forma de su ejercicio: \#la mora de un período entero en el pago de la renta, dará derecho al arrendador...\#. Este derecho legal del arrendador no excluye que las partes puedan pactar la terminación ipso facto del contrato. Lo anterior es sin perjuicio de las limitaciones procedimentales que sí establece el artículo 4 de la ley 18.101 y que en la especie se cumplieron a cabalidad. En efecto, incluso si las partes pactaron la terminación ipso facto del contrato, el arrendador solo puede solicitar judicialmente la restitución del inmueble. Pero en este caso, el arrendatario no podrá ya 
enervar esta acción de restitución mediante el pago de lo adeudado. En atención a lo razonado, esta Corte concluye que la sentencia impugnada no ha incurrido en la infracción del artículo 1977 del Código Civil que se le reprocha.

Coincidimos con esta lectura que hace la Corte Suprema, desde que, efectivamente, los artículos 1977 del Código Civil y 10 de la Ley 18.101 reconocen al arrendador el derecho a terminar el contrato y la forma de ejercerlo, por lo que mal podría estimarse aplicable el artículo 19 de la citada ley, norma que refiere a los derechos del arrendatario.

A pesar de lo expresado, hemos de advertir que la validez de esta cláusula resolutoria por el no pago de rentas igualmente podría ponerse en duda, no por los argumentos de la Corte de Apelaciones de Santiago, sino porque podría considerarse inválida por estimarse como contraria al orden público —afectación de la libertad contractual y del principio de igualdad presupuesto de la voluntad contractual - y entender que, por esta razón, adolece de objeto ilícito, lo que da lugar a la nulidad absoluta parcial del contrato. La nulidad procedería por aplicación de las normas del Derecho común. Sobre el particular, hemos de prestar atención a la sentencia de la Corte de Apelaciones de Santiago, de 4 de junio de 2010, que declaró nula una cláusula penal en un contrato de leasing por estimarla abusiva. En la sentencia se lee:

Corresponde revocar lo decidido en anterior instancia con referencia a la obligación de pagar la cláusula penal pactada, toda vez que el reclamo efectuado obliga al tribunal a considerar las circunstancias del contrato en que aparece de manifiesto la falta de reciprocidad en las obligaciones y derechos de ambos contratantes, con desequilibrio importante para una de ellas y afectación de principios básicos de la libertad contractual, que impiden se considere la existencia de un justo equilibrio de las contraprestaciones, generando en consecuencia una cláusula abusiva a la que debe privarse de validez, en cuanto ella obliga a pagar al demandado por concepto de avaluación anticipada de perjuicios un $50 \%$ de las rentas pendientes de vencimiento al momento del incumplimiento, sin que ello altere la vigencia de la obligación principal ${ }^{37}$.

Este mismo razonamiento de la Corte de Apelaciones de Santiago puede trasladarse a una cláusula resolutoria impuesta, no negociada por los contratantes y justificar, de este modo, su carácter de abusivo y la necesidad de privarle de validez.

Incluso, los Tribunales podrían ir más lejos y aplicar, a contratos de arrendamientos — por tratarse de contratos de adhesión dirigidos por una ley especial, la Ley 18.101-, la norma del artículo 16, letra g) de la Ley 19.496, y anular directamente la cláusula por abusiva, con lo cual extienden el ámbito de aplicación de la citada ley. Así se han pronunciado respecto de ofertas de compra y contratos de promesa de compraventa de inmuebles entre un consumidor de la vivienda y el propietario primer vendedor al que refiere el artículo 18 de la Ley General de Urbanismo y Construcciones. Así podemos citar dos sentencias de Corte de Apelaciones.

La primera, de la Corte de Apelaciones de Santiago, 3 de junio de $2014^{38}$. La Corte se pronuncia sobre un contrato de compraventa de inmuebles en que la demandada alegaba que la norma aplicable al caso era la Ley General de Urbanismo y Construcciones, y declara:

Que ha de tenerse en cuenta que las conductas que el libelo denuncia, en síntesis dicen relación con el cambio unilateral de las condiciones del contrato, en perjuicio de los consumidores; las cuales se han cometido en las ofertas de compras, pudiéndose constatar, las deficiencias del producto, con la entrega de las viviendas a cada uno de los consumidores. De esta forma no se trata de las materias que regula la Ley General de Urbanismo y Construcción, como pretende la demandada (...).

Y, la segunda, de la Corte de Apelaciones de Concepción, de 18 de agosto de $2016^{39}$, en la que se expresa:

Que, en el presente caso, dada la intención original de los contratantes, no es posible anular solo las cláusulas del contrato de promesa de compraventa que se han declarado abusivas, de modo que por imperativo legal, ha de declararse nulo, en su integridad, el referido contrato.

En síntesis, si bien las partes están facultadas para incorporar cláusulas resolutorias que modifiquen la regla del artículo 1489 del Código Civil, tales cláusulas deben ser lícitas y no lo serán cuando ellas vulneren alguna disposición de orden público, lo que provoca su nulidad. Como podemos advertir, la respuesta está en el citado artículo 1887 del Código Civil ${ }^{40}$ o cuando el Tribunal, por tratarse de un contrato por adhesión o de 
una cláusula impuesta, extienda la aplicación de la letra g) del artículo 16 de la Ley 19.496, a contratos que incorporen una cláusula resolutoria.

Así lo reconoce BEATRIZ GREGORACI, al expresar:

Siguiendo la clasificación de los límites inherentes a toda cláusula contractual (...) (límites de contenido, de interpretación y de ejercicio), cabe afirmar, en primer lugar, que los límites generales de contenido de la libertad contractual son la ley imperativa, la moral y el orden público (artículo 1255 CC).

Si la cláusula resolutoria expresa negociada no viola este límite (que será el caso más frecuente) y existe duda en la interpretación de la cláusula, esta debe decidirse en la línea de la buena fe y del Derecho dispositivo (límite de la interpretación).

En fin, el tercer y último de los límites es la adecuación de su ejercicio a la buena fe (artículo 7.1 CC) (...) ${ }^{41}$.

\section{Eficacia de la cláusula resolutoria automática}

El segundo problema refiere a la eficacia de una cláusula de resolución automática o del pacto comisorio calificado por el solo hecho del incumplimiento. La cuestión es si esta clase de pactos producen o no el efecto querido por los contratantes o si, por el contrario, el acreedor tiene el derecho a atajar el efecto resolutorio, insistiendo en el cumplimiento, exigiéndolo, más una indemnización de daños o ejercitando la pretensión indemnizatoria autónoma.

Las partes, ejerciendo su libertad contractual, pueden introducir al contrato una cláusula de resolución de pleno derecho, cuestión indiscutida; y por aplicación del principio de la fuerza obligatoria no cabría más que respetar lo querido por los contratantes: la resolución de pleno derecho. Esta es una lectura acorde con una mirada tradicional de la regla de la fuerza obligatoria del artículo 1545 del Código Civil. Esta parece ser la postura de PIZARRO-WILSON, quien, a propósito de la compatibilidad entre la cláusula resolutoria por comunicación y la acción resolutoria del artículo 1489 del Código Civil, afirma:

Acá resulta relevante la distinción entre el pacto comisorio calificado en otros contratos diversos a la compraventa y a la obligación de pagar el precio en que se ha estipulado el efecto resolutorio de pleno derecho de aquella cláusula resolutoria en que el acreedor debe manifestarse para que opere la resolución. Solo en esta última está abierta la posibilidad al acreedor de judicializar la resolución ejerciendo la acción resolutoria, pues tratándose de un pacto comisorio calificado la resolución se generó por el mero incumplimiento sin que ninguna de las partes pueda evitarlo ${ }^{42}$.

Más adelante, el autor nos explica que, en su opinión, la diferencia entre una cláusula resolutoria y un pacto comisorio calificado es precisamente que en este último "Basta el incumplimiento para entender verificada la resolución”, entendiendo que es inherente a este último el efecto de pleno derecho ${ }^{43}$.

Finalmente, afirma:

Las partes pueden otorgarle o no el efecto resolutorio de pleno derecho al incumplimiento, no pudiendo exigirse una manifestación de voluntad mediante un acto recepticio si las partes no lo han querido. Desde una perspectiva práctica parece conveniente que así sea, pero la ausencia de esa condición no puede introducirse por vía de interpretación contra la voluntad de las partes. Lo que las partes convinieron fue un pacto comisorio calificado y no una cláusula resolutoria ${ }^{44}$.

Sin embargo, encontramos otra mirada - que es la que aquí defendemos- que conecta de modo necesario a la cláusula resolutoria con la facultad de resolver del artículo 1489 del Código Civil —cuya naturaleza jurídica es la de constituir un derecho potestativo o de configuración-, ahora modelada convencionalmente, siendo este uno de los argumentos para negar el efecto resolutorio automático por el solo incumplimiento. Y conforme con la naturaleza de derecho potestativo o de configuración, la resolución, indefectiblemente, requiere de un acto recepticio por el cual el acreedor comunique al deudor su voluntad de resolver el contrato. A este argumento se suma otro: el carácter renunciable del efecto resolutorio conforme con el artículo 12 del Código Civil, desde que este cede solo a favor del acreedor y habida cuenta de tal carácter, no obstante lo pactado por las partes, el efecto resolutorio siempre sería una opción del acreedor. 
Por estas consideraciones, como de lo que se trata es del remedio de la resolución del contrato, pese a lo acordado por las partes, ella siempre requerirá de un acto recepticio o de una comunicación del acreedor al deudor; en todo caso, el primero conserva su opción de ejercitar otro remedio distinto en lugar de la resolución, bien sea exigiendo el cumplimiento o reclamando una indemnización. Por lo demás, así se desprende del artículo 1878 del Código Civil que, aunque sea norma aplicable al pacto comisorio en la compraventa por el no pago del precio, reconoce que el pacto comisorio — sin distinguir si es simple o calificado- no priva al vendedor de la opción de ejercer la pretensión de cumplimiento.

La Corte Suprema, en sentencia de 30 de diciembre de 2009, recoge esta segunda lectura, privando de eficacia a la cláusula de resolución automática, al expresar:

No obstante lo anterior, atendido su origen histórico y el principio de la autonomía de la voluntad que informa al derecho privado, resulta indiscutible actualmente para la doctrina y la jurisprudencia que el pacto de este tipo de estipulaciones no se encuentra limitado únicamente a la compraventa, pudiendo acordarse en cualquier tipo de convenciones o negocios.

Del mismo modo, debe también considerarse que afirmar que el mero incumplimiento acarrea la resolución de contrato importa, desde ya contradecir, la evolución comparada de la institución y sus desarrollos dogmáticos más modernos, todos los cuales, como se ha dicho, tanto en los ordenamientos que contemplan el pacto comisorio de modo general o únicamente a propósito del contrato de compraventa, estiman fundamental para que la resolución acontezca, un acto unilateral recepticio por parte del acreedor diligente en el sentido de prevalerse de la cláusula 45 .

Si nos preguntamos acerca de la conveniencia de estas cláusulas, la respuesta es evidente: no son convenientes, porque respetar la voluntad o la ley del contrato puede llevar a que la suerte del contrato quede entregada al deudor, quien para dejarlo sin efecto le bastará incumplir lo pactado ${ }^{46}$.

En fin, no hay duda de que una cláusula como la presentada — de resolución automática — puede originar controversia en torno a su eficacia, de modo que si el propósito de las partes es modular la resolución judicial, precisamente con la finalidad de superar sus inconvenientes, por qué no replantearnos esta cláusula, al reconocerle siempre al acreedor la facultad de resolver o no el contrato. En otros términos, sustituir el efecto resolutorio automático por la facultad de resolver en manos del acreedor, pasando de una resolución automática a otra por comunicación. Así, evitamos una posible discusión que obstaculizará aquello que las partes persiguen al incorporar una cláusula resolutoria, esto es, modular convencionalmente la facultad que reconoce el artículo 1489 del Código Civil y favorecer la funcionalidad del tráfico.

\section{Especificidad de la cláusula resolutoria: definición del incumplimiento esencial}

Es usual que en la práctica contractual nos encontremos con cláusulas que reconocen al acreedor la facultad de resolver el contrato e, incluso, disponen la resolución automática, para el evento de que la otra parte incumpla cualquiera de las obligaciones contraídas o bien declaran que, para efectos de la resolución o terminación del contrato, las partes elevan a la calidad de esencial todas las obligaciones que impone el presente contrato.

Sobre el particular conviene prestar atención a las palabras de RAFAEL ANTONIO VERDERASERVER:

La cuestión cobra una especial importancia a la vista de la frecuencia (muy a menudo convertidas en auténticas cláusulas de estilo) con las que se incluyen en las estipulaciones contractuales condiciones resolutorias de perfiles difusos o se indica, como regla de cierre, que todas las obligaciones contractuales (sean cuales sean) tienen el carácter esencial para las partes y permiten la resolución del contrato ${ }^{47}$.

El autor entiende que, respecto de estas cláusulas resolutorias, cabría el control judicial sobre si el incumplimiento en que se funda la resolución tiene o no el carácter de esencial, pasando por sobre la ley del contrato, pudiendo declarar la impertinencia de la resolución ${ }^{48}$.

En una sentencia de 27 de septiembre de $2016^{49}$, la Corte Suprema se pronunció sobre cómo opera la resolución en un caso de cláusula resolutoria por comunicación e indirectamente reconoce plenos efectos a 
una cláusula contenida en unas "condiciones generales", que confiere a una de las partes la facultad de resolver el contrato frente a cualquier incumplimiento de las obligaciones contraídas por la otra.

El recurrente alega que procede la resolución judicial según el art. 1489 Código Civil, dado que la otra parte se limitó a comunicar la resolución sin especificar el incumplimiento en que la funda. En la sentencia se lee:

DECIMOQUINTO: Que del análisis del anexo "Condiciones Generales", que forma parte integrante de cada uno de los contratos suscritos por las partes, se aprecia que estas expresamente contemplaron la facultad de poner término anticipado, ipso facto y unilateralmente al contrato ante cualquier incumplimiento de las obligaciones que eran de cargo de INELCO.

Es decir, los contratantes expresamente establecieron la procedencia del pacto comisorio calificado, sin necesidad de declaración judicial previa, de manera que se debe estar a esa manifestación de voluntad, la que no puede ser desconocida por ninguna de las partes que la suscribieron. Luego, siendo un hecho establecido en la causa que INELCO incumplió sus obligaciones al no emplear la debida diligencia y cuidado en la ejecución de las obras encomendadas, la demandada principal y demandante reconvencional se encontraba facultada para poner término a la relación contractual que la vinculaba con la contraria, resultando para ello suficiente la comunicación efectuada mediante carta, sin que sea exigible en la especie, dado los términos del pacto comisorio calificado, accionar ante el órgano jurisdiccional con el fin de perseguir que este declare la resolución de los contratos.

Sin embargo, encontramos otras dos sentencias que restan eficacia a una cláusula que tipifica genéricamente ${ }^{50}$ los incumplimientos con trascendencia resolutoria.

En la primera, de 3 de julio de 2008, pese al tenor literal de la cláusula "genérica" de incumplimiento esencial, la Corte de Apelaciones de Santiago ${ }^{51}$ no da lugar a la resolución dado que se trata de una obligación accidental y su incumplimiento solo daría lugar a la resolución si las partes lo hubieren acordado expresamente. Y, en la segunda, la Corte de Apelaciones de La Serena desconoce efectos a la cláusula resolutoria que declara que cualquiera falta en el cumplimiento del contrato daba derecho al arrendador a hacerlo cesar, sin que el arrendatario pueda por ello hacer reclamo alguno o cobrar perjuicios. El arrendatario incurrió en mora respecto de un canon de arrendamiento.

Así también la Corte Suprema lo ha sostenido de manera explícita, al conocer un caso en que se demandó la resolución de la compraventa de un inmueble, por no pago de una de las cuotas convenidas. Señaló la Corte lo siguiente:

A su vez, la interpretación criticada por el recurrente, guarda relación con el carácter excepcional que se le debe atribuir a la condición resolutoria, con la circunstancia que esta puede ser modificada e incluso renunciada por la voluntad de las partes y con el hecho que el efecto resolutorio de un pacto comisorio solo puede surgir de una cláusula redactada en términos claros y precisos. De este modo, si las partes no estipulan una cláusula precisa de resolución para el caso del no pago de precio, el juez debe privilegiar la conservación del contrato, más aún si como ocurre en la especie, los contratantes postergaron la acción de resolución a los resultados del cobro del saldo insoluto, cumplimiento forzado que al no haberse ejercido por el recurrente, impide que el actor pueda accionar directamente la resolución de la compraventa de marras, tal como resolvieron los jueces del grado 52 .

Esta línea jurisprudencial resulta coherente con las exigencias de la buena $\mathrm{fe}^{53}$, dado que una cláusula genérica como la descrita necesariamente nos hace regresar al artículo 1489 del Código Civil, conservando el juez la facultad para calificar si el incumplimiento es o no esencial ${ }^{54}$. Por esta razón, el Código Civil y de Comercio argentino, el Código Civil italiano, el Código Civil peruano y los PLDC exigen que se trate de obligaciones debidamente determinadas o identificadas. Es más, en el caso argentino esta fue la modificación que introdujo el legislador, claramente con la finalidad de evitar un ejercicio abusivo y contrario a la buena fe de la facultad resolutoria. El legislador recoge la doctrina jurisprudencial imperante en esa época.

Podría pensarse que nuestra posición sería contraria a la regla de la fuerza obligatoria del contrato del artículo 1545, dado que supone pasar por encima de lo querido por las partes, y lo querido por las partes fue que ante cualquier incumplimiento procede la resolución del contrato. Empero, entendemos que la regla de la buena fe objetiva del artículo 1546 del Código Civil es la que viene a morigerar el alcance de este principio 
55. Si el acreedor intenta resolver el contrato, invocando una cláusula conforme la cual todo incumplimiento es esencial, estaría contrariando las exigencias de la buena fe objetiva.

Por lo demás, este tipo de cláusulas normalmente son el resultado de una imposición de una parte a otra, que se reserva la primera la facultad de resolver el contrato. Y la pregunta que uno debiera hacerse es ¿ una persona razonable en la misma posición de la parte contractual y en pie de igualdad, aceptaría una cláusula como esta?, ¿consentiría libremente en ella? Todo parece indicar que la respuesta sería negativa. Este razonamiento podría llevarnos a la misma solución que hemos presentado con respecto a la cláusula resolutoria por el no pago de rentas, impuesta por el arrendador al arrendatario, pudiendo concluir que es nula, sea por aplicación de las normas del derecho común, sea por aplicación de la letra g) del artículo 16 de la Ley 19.496.

No obstante lo anterior, nuestra opinión es que este tipo de cláusula resolutoria genérica es incompleta y lo es porque omite un elemento fundamental, a saber, la definición específica de aquellos incumplimientos u obligaciones cuya infracción tiene trascendencia resolutoria. Y como es incompleta, el desplazamiento del artículo 1489 del Código Civil es parcial, por lo cual el juez conserva la facultad de calificar si el incumplimiento invocado es o no esencial.

La exigencia se aprecia con nitidez, si recordamos aquella condición que torna procedente el remedio resolutorio, como la esencialidad del incumplimiento. La doctrina y la jurisprudencia ${ }^{56}$ están contestes en que, como presupuesto de la resolución contractual, la gravedad o esencialidad del incumplimiento es determinante. Si el incumplimiento es irrelevante o insignificante, la resolución será improcedente ${ }^{57}$. Para acometer la calificación del incumplimiento, se ha recurrido a un conjunto de criterios que permiten mensurar si la falta de cumplimiento reviste o no la esencialidad exigida como condición de procedencia del remedio ${ }^{58}$ . Entre ellos, si las partes modularon y definieron una obligación como esencial, o la elevaron a tal carácter.

Por lo anterior, resulta particularmente gravitante la calificación que las partes asignen al incumplimiento del contrato. Es decir, en uso de su voluntad, al tiempo de configurar la cláusula resolutoria, y especificar el tipo de incumplimiento o la obligación incumplida que le servirán de detonante, las partes definen cuándo aquel será esencial o no ${ }^{59}$. De esta manera, se satisfará el requisito antes mencionado, con la precisión y especificidad de los incumplimientos resolutorios en este tipo de cláusulas.

Un caso resulta ilustrativo sobre este punto, aunque hemos de advertir que el contrato sobre el que recae no contiene una cláusula resolutoria, sino que se limita a definir ciertos contenidos suyos como esenciales ${ }^{60}$.

Una empresa arrienda a otra un inmueble, con el objeto de instalar y operar en él un campo de minigolf. Celebrado el contrato, la arrendataria se vio imposibilitada de llevar adelante el proyecto del campo de minigolf, pues la normativa urbanística prohibía el uso comercial de ese inmueble, cuestión que no le fue informada por parte de la arrendadora al tiempo del perfeccionamiento del contrato. La arrendataria demanda la resolución del contrato y la indemnización de perjuicios. La Corte de Apelaciones de Santiago acogió la demanda de terminación del contrato, aduciendo que las partes incorporaron al contrato, como una obligación esencial, el que el inmueble arrendado estuviera en condiciones de ser utilizado para los fines para los que se celebró el contrato, esto es, instalar y operar un campo de minigolf.

Finalmente, hemos de puntualizar que, si se cumple la exigencia de la especificidad de la cláusula en cuanto ella precise los incumplimientos o las obligaciones que hacen procedente la resolución, el juez carece de facultades para revisar el acuerdo y recalificar el incumplimiento a objeto de dilucidar si reviste o no el carácter de esencial. Al juez no le quedará más que respetar lo querido por las partes. Así parece recogerlo, aunque oblicuamente, la citada sentencia de la Corte de Apelaciones de Santiago, de 3 de julio de $2008^{61}$, al restar eficacia a una cláusula "genérica" de incumplimiento esencial respecto de una obligación que el Tribunal califica de accidental y declara que su incumplimiento solo daría lugar a la resolución, si las partes lo hubiesen acordado expresamente ${ }^{62}$. 


\section{Coexistencia de la cláusula resolutoria y la resolución judicial del artículo 1489 del Código Civil}

Una última cuestión por considerar es si las partes, al incorporar una cláusula resolutoria, excluyen la resolución judicial del artículo 1489 del Código Civil ${ }^{63}$; en otros términos, ¿̇son o no compatibles ambos regímenes de resolución?

En esta materia, hay dos posiciones. La primera que entiende que la resolución convencional al tener su origen en el acuerdo de las partes, convive con la resolución judicial del artículo 1489 del Código Civil, de modo que el acreedor podría inclinarse por resolver extrajudicial o judicialmente. Y la segunda, que niega la compatibilidad de ambas resoluciones en atención a que la resolución convencional constituye un elemento accidental del contrato que desplaza la norma de la resolución judicial. Aceptar la compatibilidad y reconocer la opción al acreedor entre ambas resoluciones, de acuerdo con esta segunda posición, implicaría admitir la modificación unilateral del contrato por parte de esta última parte. Veamos.

Una sentencia de la Corte Suprema, de 9 de diciembre de 2008, que se pronuncia sobre la posibilidad de demandar la resolución judicial conforme el artículo 1489 del Código Civil, a pesar de que las partes incorporaron al contrato de arrendamiento un pacto comisorio calificado con comunicación, la admite y expresa sobre el punto en su considerando octavo:

\footnotetext{
Que, sin perjuicio de lo antes indicado, el incumplimiento contractual en que ha incurrido la arrendataria ha hecho operar, en virtud de lo dispuesto en el artículo 1489 del Código Civil, la condición resolutoria envuelta tácitamente en todo contrato bilateral, que, en el caso del arrendamiento, por su especial naturaleza de contrato de tracto sucesivo, opera como causal de término o expiración del mismo y no, en estricto rigor, de resolución. Pues bien, el hecho de haber estipulado las partes un pacto comisorio no puede ser obstáculo, como se afirma en el recurso, para el ejercicio de la acción resolutoria que emana de la condición resolutoria tácita y al haberse verificado el hecho de que pendía tal condición, según se tuvo por acreditado por los jueces de la instancia, debió la sentencia haber declarado el término del arrendamiento y, consecuencialmente, condenar al pago de las rentas insolutas 64 .
}

Esta es la posición que defiende CARLOS PIZARRO-WILSON, quien afirma que el acreedor puede renunciar a la cláusula resolutoria por aplicación del artículo 12 del Código Civil y demandar la resolución de acuerdo con lo prescrito por el artículo 1489 del Código Civil. El autor señala la independencia de la resolución judicial respecto de la judicial, al afirmar que tal independencia "resulta de su fundamento en la voluntad de las partes, siendo una sanción convencional al incumplimiento contractual, diverso a la resolución judicial, lo que explica que el acreedor pueda optar por una o por otra" ${ }^{65}$.

Si bien la respuesta a esta interrogante puede quedar abierta, porque una cláusula resolutoria puede ser incompleta o, si se prefiere, no exhaustiva o de cierre, lo cual deja abierta la posibilidad de acudir a la resolución judicial. La definición sobre si la cláusula es o no exhaustiva refiere a una cuestión de interpretación del sentido y alcance de la estipulación contractual.

Sin embargo, no podemos compartir la idea de que el acreedor tiene la opción entre la resolución por comunicación (convencional) y la resolución judicial, a pretexto que la cláusula resolutoria es renunciable conforme con el artículo 12 del Código Civil. La cláusula resolutoria no está establecida en el solo interés del acreedor, sino en el de ambas partes. Por estas cláusulas, las partes distribuyen el riesgo de la resolución, confiriendo certeza a ambas partes acerca de cuándo procede y cuándo no la resolución. Tal cláusula es fruto de una negociación e integra el contrato, de modo que reconocer al acreedor la facultad de renunciar a ella, implicaría aceptar una modificación unilateral del contrato. Creemos que no podemos confundir el carácter renunciable de la facultad resolutoria, e incluso del efecto resolutorio en una cláusula de resolución automática, con el pretendido carácter renunciable de la cláusula para el acreedor, teniendo en especial consideración que ella, como otras cláusulas, integran el contenido del contrato. 
Otra cosa, como dijimos, es que de la interpretación de la cláusula resolutoria, concluyamos que la común intención de los contratantes no fue limitar la resolución a las hipótesis previstas por la cláusula contractual, sino dejar abierta la procedencia de la resolución judicial. La conclusión debe ser que la disciplina de la resolución convencional que introdujeron las partes no es exhaustiva, razón por la cual es compatible con la resolución judicial del artículo 1489 del Código Civil chileno. La resolución convencional convive con la judicial y queda por definir el preciso ámbito de ambas.

Sin perjuicio de lo anterior, hemos de advertir que puede presentarse un caso en el que la cláusula resolutoria se desplaza y le permite al acreedor volver al derecho dispositivo, lo cual priva al deudor, de este modo, de la protección que ella le confiere. Pensamos en el caso de los incumplimientos dolosos. Es evidente que cuando las partes introducen una cláusula resolutoria la prevén para incumplimientos casuales o meramente negligentes (culpa leve), no para los dolosos o con culpa grave.

Si este es el caso, que el incumplimiento del deudor es doloso o con culpa grave, y si consideramos que la cláusula resolutoria confiere una dosis importante de protección al deudor, pues limita los efectos nocivos de su incumplimiento: la aplicación de un principio transversal en materia de remedios contractuales impide al deudor que comete dolo o culpa grave invocar la protección que el mismo contrato le confiere. Hemos de coincidir en que el deudor ha cometido una infracción contractual, no solo al desconocer la regla convenida, sino también al despreciar el interés de su contraparte ${ }^{66}$.

Por este orden de consideraciones, el acreedor queda autorizado a proceder como si se tratase de una cláusula no escrita, lo que en este caso se traduce en volver al derecho común respecto del remedio de la resolución contractual y transitar, ahora de vuelta, desde una resolución por comunicación a una por declaración judicial, siendo aplicable la regla del artículo 1489 del Código Civil ${ }^{67}$.

\section{Conclusiones}

1. Las partes tienen la facultad de incorporar una cláusula resolutoria y modificar así el artículo 1489. Esta cláusula, junto con definir específicamente los incumplimientos con trascendencia resolutoria, reconoce al acreedor la facultad de resolver el contrato si así lo estima conveniente, que debe comunicar al deudor su voluntad en este sentido. Si es el caso, la resolución se producirá extrajudicialmente.

2. Las cláusulas resolutorias son lícitas y plenamente válidas, a menos que infrinjan normas imperativas o de orden público o que, por aplicación de la Ley 19.496, sean calificadas como abusivas y, por ende, nulas.

3. Si bien las partes, en ejercicio de su libertad contractual, están autorizadas para incorporar cláusulas de resolución automática, la propia naturaleza de la facultad de resolver el contrato como derecho potestativo y el carácter renunciable del efecto resolutorio, deja a salvo al acreedor, pese a lo pactado, la opción entre la resolución y los otros remedios. La resolución convencional siempre requiere de un acto recepticio o de una comunicación de parte del acreedor al deudor.

4. La cláusula resolutoria debe definir o tipificar específicamente y con precisión los incumplimientos esenciales o las obligaciones cuyo incumplimiento tiene trascendencia resolutoria. Una cláusula genérica - que no cumple con esta exigencia de la especificidad- es una cláusula incompleta y el juez tiene la facultad de calificar si el incumplimiento en que se funda la resolución es o no esencial.

5. En síntesis, la incorporación de una cláusula resolutoria modifica el artículo 1489, y lo desplaza, de modo que mal podemos compartir la idea de que la cláusula sea renunciable, porque el acreedor, al prescindir de la cláusula, estaría modificando unilateralmente el contrato. Otra cosa es que la cláusula no sea exhaustiva, lo que deja abierta la posibilidad de recurrir al artículo 1489 del Código 
Civil; o que siéndolo, el deudor incurra en un incumplimiento doloso o con culpa grave, en cuyo caso al acreedor le está permitido volver al derecho común y prescindir de la cláusula resolutoria.

\section{Bibliografía}

\section{Libros}

ABELIUK-MANASEVICH, RENÉ, Las obligaciones, Tomo I (3ª ed., Thomson Reuters, Santiago, 2014).

ALESSANDRI-RODRÍGUEZ, ARTURO, De la compraventa y de la promesa de venta, Tomo II (Editorial Jurídica de Chile, Santiago, 2003).

ALFARO ÁGUILA-REAL, JESÚS, Las condiciones generales de la contratación (Civitas, Madrid, 1991).

ÁLVAREZ-VIGARAY, RAFAEL, La resolución de los contratos bilaterales por incumplimiento (Comares, Granada, 2009).

CARRASCO-PERERA, ÁNGEL, Derecho de contratos (2a ed., Aranzadi, Pamplona, 2017).

CLARO-SOLAR, LUIS, Explicaciones de derecho civil chileno y comparado, vol. 5, De las obligaciones (Editorial Jurídica de Chile, Santiago, 1979).

CLARO-SOLAR, LUIS, Lecciones de derecho civil chileno y comparado, IX, Obligaciones II (Nascimento, Santiago, 1937).

CLEMENTE-MEORO, MARIO E., La facultad de resolver los contratos por incumplimiento (Editorial Tirant lo Blanch, Valencia, 1998).

DÍEZ-PICAZO Y PONCE DE LEÓN, LUIS, Fundamentos del Derecho Civil Patrimonial, volumen I, Teoría del Contrato (Civitas, Pamplona, Navarra, 2007).

ELGUETA-ANGUITA, AUGUSTO, Resolución de contratos y excepción de pago (Editorial Jurídica de Chile,

Santiago, 1981).

GREGORACI, BEATRIZ, Cláusula resolutoria y control del incumplimiento (Derecho Privado, Agencia Estatal Boletín Oficial del Estado, BOE, Madrid, 2015). Disponible en: https://www.boe.es/publicaciones/biblioteca_juridica/publicacion.php?id=PUB-PR-2015-40_CL\%C3\% 81USULA_RESOLUTORIA_Y_CONTROL_DEL_INCUMPLIMIENTO\&tipo $=$ L\&modo $=1$

LÓPEZ-SANTA MARÍA, JORGE \& ELORRIAGA DE BONIS, FABIÁN, Los contratos, Parte general (6a ed., Thomson Reuters, Santiago, 2017).

MAZA-GAZMURI, ÍNIGO DE LA; PIZARRO-WILSON, CARLOS \& VIDAL-OLIVARES, ÁLVARO, coords., eds., Los Principios Latinoamericanos de Derecho de los Contratos, Texto, presentación y contenidos fundamentales (Derecho Privado, Agencia Estatal Boletín Oficial del Estado, BOE, Madrid, 2017). Disponible en: https://ww w.boe.es/publicaciones/biblioteca_juridica/abrir_pdf.php?id=PUB-PR-2017-44

MEJÍAS-ALONZO, CLAUDIA, El incumplimiento resolutorio en el Código Civil (Abeledo Perrot, Legal Publishing, Santiago, 2011).Disponible en: https://www.academia.edu/37739960/El_incumplimiento_resolutorio_en_e 1_C\%C3\%B3digo_Civil

MORALES-MORENO, ANTONIO MANUEL, Incumplimiento del contrato y lucro cesante (Thomson Civitas, Pamplona, Navarra, 2010).

PALAZÓN-GARRIDO, MARÍA LUISA, Los remedios frente al incumplimiento en el Derecho comparado (Cizur Menor, Editorial Aranzadi, Pamplona, Navarra, 2014).

PEÑAILILLO-ARÉVALO, DANIEL, Obligaciones. Teoría general y clasificaciones. La resolución por incumplimiento (Editorial Jurídica de Chile, Santiago, 2003).

PERLINGIERI, PIETRO, El derecho civil en la legalidad constitucional según el sistema italo-comunitario de las fuentes ( $3^{\mathrm{a}}$ ed., AGUSTÍN LUNA-SERRANO \& CARLOS MALUQUER DE MOTES Y BERNET, trads., Dykinson, Madrid, 2008).

RAMOS-PAZOS, RENÉ, De las obligaciones (3a ed., LexisNexis, Santiago, 2008). 


\section{Contribución en obras colectivas}

BARROS-BOURIE, ENRIQUE, Finalidad y alcance de las acciones y los remedios contractuales, en Estudios de Derecho Civil III, Jornadas Nacionales de Derecho Civil, Valparaíso 2007, 403-428 (ALEJANDRO GUZMÁN-BRITO, ed., Valparaíso, LexisNexis, 2008).

GANDARILLAS-SERANI, CRISTIÁN, Algunas consideraciones acerca del deber de mitigación o minimización del daño frente al incumplimiento contractual, en Estudios de Derecho Civil IV, 431-450 (CARLOS PIZARROWILSON, coord., LegalPublishing, Santiago, 2009).

MIQUEL-GONZÁLEZ, JOSÉ MARÍA, Comentario al art. 82 TR-LGDCU, en Comentarios a las normas de protección de los consumidores. Texto refundido (RDL 1/2007) y otras leyes y reglamentos vigentes en España y en la Unión Europea, 711-753 (SERGIO CÁMARA-LAPUENTE, dir., Editorial Constitución y Leyes, COLEX, Coruña, 2011).

MONTES-PENADÉS, VICENTE LUIS, Artículo 1124 CC, en Comentarios al Código Civil y Compilaciones Forales, Tomo XV, Volumen 1, Artículos 1.088 a 1.124, 1215-1306 (MANUEL ALBALADEJO-GARCÍA, dir., Editoriales de Derecho Reunidas, Edersa, Madrid, 1989).

MORALES-MORENO, ANTONIO MANUEL, Evolución del concepto de obligación en Derecho español, en La modernización del derecho de obligaciones, 17-54 Evolución del concepto de obligación en Derecho español (ANTONIO MANUEL MORALES-MORENO, Thomson-Civitas, Madrid, 2006).

PIZARRO-WILSON, CARLOS, Cláusula resolutoria y pacto comisorio calificado. Tan lejos, tan cerca, en Estudios de Derecho Civil VIII, Jornadas Nacionales de Derecho Civil, Santa Cruz, 2012, 357-368 (CARMEN DOMÍNGUEZ-HIDALGO, JOEL GONZÁLEZ-CASTILLO, MARCELO BARRIENTOSZAMORANO \& JUAN LUIS GOLDENBERG-SERRANO, coords., Thomson Reuters, Santiago, 2013).

PIZARRO-WILSON, CARLOS, Hacia un sistema de remedios al incumplimiento contractual, en Estudios de Derecho Civil III, Jornadas Nacionales de Derecho Civil, Valparaiso 2007, 395-402 (ALEJANDRO GUZMA\#NBRITO, ed., LegalPublishing, Santiago, 2008).

VIDAL-OLIVARES, A\#LVARO, El incumplimiento de obligaciones con objeto fungible y los remedios del acreedor afectado. Un intento de relectura de las disposiciones del Código Civil sobre incumplimiento, en El Código Civil de Chile (1855-2005), 495-550 (ALEJANDRO GUZMÁN-BRITO, ed., LexisNexis, Santiago, 2007).

VIDAL-OLIVARES, ÁLVARO, La carga de mitigar las pérdidas del acreedor y su incidencia en el sistema de remedios por incumplimiento, en Estudios de Derecho Civil III, Jornadas Nacionales de Derecho Civil, Valparaiso 2007, 795-827 (ALEJANDRO GUZMÁN-BRITO, ed., LegalPublishing, Santiago, 2008).

\section{Revistas}

BOTTESELLE-MÁRDONES, ANDREA, Elpacto comisorio como manifestación de la facultad resolutoria, 17 Revista Chilena de Derecho Privado, RChDP, 71-103 (2011). Disponible en: https://scielo.conicyt.cl/pdf/rchdp/n17/ art03.pdf

MANRIQUE, ELSA, El pacto comisorio en el Código Civily Comercial de la Nación, 7 Revista Cientifica Semestral In Iure, Ciencias Jurídicas y Notariales, 1, 25-43 (2017). Disponible en: https://revistaelectronica.unlar.edu.ar/in dex.php/iniure/article/viewFile/337/312

MAZA-GAZMURI, ÍNIGO DE LA, El control de las cláusulas abusivas y la letra g, 3 Revista Chilena de Derecho Privado, Fernando Fueyo Laneri, 35-68 (2004). Disponible en: http://fundacionfueyo.udp.cl/wp-content/upl oads/2018/06/R3.pdf

MEJÍAS-ALONZO, CLAUDIA, El incumplimiento que faculta a resolver el contrato a la luz de las disposiciones del Código Civil, VII Cuadernos de Análisis Jurídico, Colección Derecho Privado, Incumplimiento contractual. Nuevas perspectivas, 171-212 (ÍNIGO DE LA MAZA-GAZMURI, coord., Ediciones Universidad Diego Portales, Santiago, 2011). Disponible en: http://fundacionfueyo.udp.cl/wp-content/uploads/2018/06/Cuadernos-7.pd $\mathrm{f}$ 
MEJÍAS-ALONZO, CLAUDIA \& SEVERIN-FUSTER, GONZALO, La justificación funcional del pacto comisorio en la compraventa, XXX Revista de Derecho (Valdivia), 2, 87-109 (2017). Disponible en: http://revistas.uach. cl/pdf/revider/v30n2/art04.pdf

PANTALEÓN-PRIETO, ÁNGEL FERNANDO, Las nuevas bases de la responsabilidad contractual, 4 Anuario de Derecho Civil, 1719-1745 (1993). Disponible en https://www.boe.es/publicaciones/anuarios_derecho/articul o.php?id=ANU-C-1993-40171901746.

PIZARRO-WILSON, CARLOS, Las cláusulas resolutorias en el derecho civil chileno, III Cuadernos de Análisis Jurídico, Colección de Derecho Privado, 245-258 (2006). Disponible en: http://fundacionfueyo.udp.cl/wp-cont ent/uploads/2018/03/Cuadernos-de-ana\%CC\%81lisis-juri\%CC\%81dico-III.-Temas-de-contratos.pdf

SAN MIGUEL-PRADERA, LIS PAULA, La resolución por incumplimiento en la propuesta para la modernización del derecho de obligaciones y contratos: ¿lo mejor es enemigo de lo bueno?, LXIV Anuario de Derecho Civil, ADC, IV, 1685-1724 (2011). Disponible en: https://www.boe.es/publicaciones/anuarios_derecho/abrir_pdf.php?id=ANU-C-2011-40168501724_A NUARIO_DE_DERECHO_CIVIL_La_resoluci\%F3n_por_incumplimiento_en_la_Propuesta_para_la_M odernizaci\%F3n_del_Derecho_de_obligaciones_y_contratos:_\%BLo_mejora_es_enemigo_de_lo_bueno?

VERDERA-SERVER, RAFAEL ANTONIO, Cláusula resolutoria y retraso en la entrega de vivienda, Comentario a la Sentencia de 13 de noviembre de 2013, 95 Cuadernos Civitas de Jurisprudencia Civil, CCJC, 467-492 (2014).

VIDAL-OLIVARES, ÁLVARO, La construcción de la regla contractual en el derecho civil de los contratos, XXI Revista de Derecho de la PUCV, Revista de Derecho de la Pontificia Universidad Católica de Valparaiso, 209-227 (2000). Disponible en: http://www.rdpucv.cl/index.php/rderecho/article/view/464/434

VIDAL-OLIVARES, ÁLVARO, La noción de incumplimiento esencial en el Código Civil, XXXII Revista de Derecho de la PUCV, Revista de Derecho de la Pontificia Universidad Católica de Valparaiso, 221-258 (2009). Disponible en: https://scielo.conicyt.cl/pdf/rdpucv/n32/a06.pdf

\section{Tratados internacionales y soft law}

Commission on European Contract Law, Principles of European Contract Law, PECL. Disponible en: https://cisgw 3.law.pace.edu/cisg/text/textef.html

Instituto Internacional para la Unificación del Derecho Privado, UNIDROIT, Principios sobre Contratos Comerciales Internacionales, PCCI, 2016. Disponible en: https://www.unidroit.org/spanish/principles/contracts/principle s2010/blackletter2010-spanish.pdf, http://www.unidroit.org/unidroit-principles-2016/official-languages/eng lish-integral

Organización de Naciones Unidas, ONU, Comisión de las Naciones Unidas para el Derecho Mercantil Internacional, CNUDMI, Convención de las Naciones Unidas sobre los Contratos de Compraventa Internacional de Mercaderías, Viena, 11 de abril de 1980. Disponible en: https://www.uncitral.org/pdf/spanish/texts/sales/cisg /V1057000-CISG-s.pdf

\section{Normativa internacional}

Argentina, Código Civil y de Comercio de la Nación, Ley 26.994, 32.985 Boletín Oficial, 8 de octubre de 2014. Disponible en: http://servicios.infoleg.gob.ar/infolegInternet/anexos/235000-239999/235975/norma.htm

Brasil, Código Civil, Lei 10.406, Diário Oficial da União, 10 de janeiro de 2002. Disponible en: http://www.planalt o.gov.br/ccivil_03/LEIS/2002/L10406.htm

Francia, Código Civil, 21 de marzo de 1804. Disponible en: https://www.legifrance.gouv.fr/affichCode.do?cidText $\mathrm{e}=$ LEGITEXT000006070721

Italia, Código Civil, Regio Decreto 262, 16 de marzo de 1942. Disponible en: https://www.altalex.com/documents /codici-altalex/2015/01/02/codice-civile 
Perú, Código Civil, Decreto Legislativo 295, Diario Oficial El Peruano, 25 de julio de 1984. Disponible en: http://sp ij.minjus.gob.pe/notificacion/guias/CODIGO-CIVIL.pdf

\section{Normativa chilena}

Chile, Código Civil, Ley de 14 de diciembre de 1855, Diario Oficial, 14 de diciembre de 1855. Disponible en: https: $/ /$ www.leychile.cl/Navegar?idNorma $=172986 \&$ idParte $=8717776$

Chile, Decreto con Fuerza de Ley 458, Ley General de Urbanismo y Construcciones, Diario Oficial, 13 de abril de 1976. Disponible en: https://www.leychile.cl/Navegar?idNorma $=13560$

Chile, Ley 18.101, que fija normas especiales sobre arrendamiento de predios urbanos, Diario Oficial, 29 de enero de 1982. Disponible en: https://www.leychile.cl/Navegar?idNorma $=29526$

Chile, Ley 19.496, que establece normas sobre protección de los derechos de los consumidores, Diario Oficial, 7 de marzo de 1997. Disponible en: https://www.leychile.cl/Navegar?idNorma=61438

\section{Jurisprudencia chilena}

Chile, Corte de Apelaciones de Chillán, 11 de julio de 2008, Rol 128-2005. Cita en línea: CL/JUR/7792/2008.

Chile, Corte de Apelaciones de Concepción, 9 de julio de 2003, Rol 347-2003. Cita en línea: CL/JUR/2481/2003.

Chile, Corte de Apelaciones de Concepción, 13 de octubre de 2005, Rol 3130-2005. Cita en línea: CL/ JUR/5607/2005.

Chile, Corte de Apelaciones de Concepción, 16 de noviembre de 2005, Rol 3461-2005. Cita en línea: CL/ JUR/1740/2005.

Chile, Corte de Apelaciones de Concepción, 23 de noviembre de 2009, Rol 584-2009. Cita en línea: CL/ JUR/3868/2009.

Chile, Corte de Apelaciones de Concepción, 4 de marzo de 2013, Rol 1502-2012. Cita en línea: CL/JUR/499/2013.

Chile, Corte de Apelaciones de Concepción, 20 de octubre de 2014, Rol 345-2014. Cita en línea: CL/ JUR/7627/2014.

Chile, Corte de Apelaciones de Concepción, 18 de agosto de 2016, Rol 159-2016. Cita en línea: CL/JUR/6802/2016.

Chile, Corte de Apelaciones de Santiago, 3 de julio de 2008, Rol 761-2006. Cita en línea: 46989 LegalPublishing.

Chile, Corte de Apelaciones de Santiago, 29 de noviembre de 2007, Rol 3073-2003. Cita en línea: CL/ JUR/3963/2007.

Chile, Corte de Apelaciones de Santiago, 4 de junio de 2010, Rol 5484-2009. Cita en línea: CL/JUR/3135/2010.

Chile, Corte de Apelaciones de Santiago, 3 de junio de 2014, Rol 8281-2013. Cita en línea: CL/JUR/2871/2014.

Chile, Corte de Apelaciones de Santiago, 6 de noviembre de 2015, Rol 8276-2015. Cita en línea: CL/JUR/6741/2015.

Chile, Corte de Apelaciones de Talca, 23 de septiembre de 2015, Rol 1953-2015. Cita en línea: CL/JUR/5742/2015.

Chile, Corte Suprema, 8 de agosto de 1996, Rol 33888-1996. Cita en línea: CL/JUR/621/1996.

Chile, Corte Suprema, 9 de abril de 2007, Rol 5869-2005. Cita en línea: CL/JUR/5818/2007.

Chile, Corte Suprema, 22 de enero de 2008, Rol 3247-2006. Cita en línea: LegalPublishing 38181.

Chile, Corte Suprema, 9 de diciembre de 2008, Rol 5821-2007. Cita en línea: CL/JUR/6929/2008.

Chile, Corte Suprema, 17 de marzo de 2009, Rol 6914-2007. Cita en línea: LegalPublishing 41820.

Chile, Corte Suprema, 23 de marzo de 2009, Rol 6856-2007. Cita en línea: LegalPublishing: 41793.

Chile, Corte Suprema, 30 de diciembre de 2009, Rol 5817-2008.

Chile, Corte Suprema, 12 de enero 2012, Rol 2319-2011. Cita en línea: CL/JUR/309/2012.

Chile, Corte Suprema, 10 de diciembre de 2012, Rol 3320-2012. Cita en línea: MJJ34056.

Chile, Corte Suprema, 21 de enero de 2013, Rol 5504-2011. Cita en línea: CL/JUR/131/2013. 
Chile, Corte Suprema, 27 de mayo de 2014, Rol 3407-2013. Cita en línea: CL/JUR/2673/2014.

Chile, Corte Suprema, 11 de mayo de 2016, Rol 4804-2015. Cita en línea: CL/JUR/3090/2016.

Chile, Corte Suprema, 2 de junio de 2016, Rol 6528-2015. Cita en línea: CL/JUR/3640/2016.

Chile, Corte Suprema, 27 de septiembre de 2016, Rol 17061-2016. Cita en línea: CL/JUR/6688/2016.

\section{Otros documentos}

PENA-GNZÁHZ, CARLOS, La resolución como ineficacia extrinseca, apunte docente (inédito)Disponible en: ht tps://www.u-cursos.cl/derecho/2008/1/D122A0415/1/material_docente/bajar?id_material=162051.

\section{Notas}

1 CARLOS PIZARRO-WILSON, Las cláusulas resolutorias en el derecho civil chileno, III Cuadernos de Análisis Jurídico, Colección de Derecho Privado, 245-258, 249 (2006).

2 La regla del artículo 1879 del Código Civil chileno establece lo siguiente: "Si se estipula que por no pagarse el precio al tiempo convenido, se resuelva ipso facto el contrato de venta, el comprador podrá, sin embargo, hacerlo subsistir, pagando el precio, lo más tarde, en las veinticuatro horas subsiguientes a la notificación judicial de la demanda”.

3 Entre ellos, LUIS CLARO-SOLAR, Explicaciones de derecho civil chileno y comparado, vol. 5, De las obligaciones, 160 (Editorial Jurídica de Chile, Santiago, 1979). RENÉ ABELIUK-MANASEVICH, Las obligaciones, Tomo I, 423 (3ª ed., Thomson Reuters, Santiago, 2014).

4 ÁLVARO VIDAL-OLIVARES, La construcción de la regla contractual en el derecho civil de los contratos, XXI Revista de Derecho de la Pontificia Universidad Católica de Valparaíso, 209-227 (2000).

5 DÍEZ-PICAZO Y PONCE DE LEÓN, al pronunciarse sobre la libertad contractual, afirma que ella significa la posibilidad de modificar, también, libremente, en los contratos regulados por la ley, el contenido legal de estos contratos y sustituirlo por otro distinto. LUIS DÍEZ-PICAZO Y PONCE DE LEÓN, Fundamentos del Derecho Civil Patrimonial, volumen I, Teoria del Contrato, 155 (Civitas, Pamplona, Navarra, 2007). Por su parte, CARRASCO-PERERA añade, más específicamente y con relación al punto de nuestro interés que, "los contratantes pueden alterar o modificar los derechos y obligaciones predeterminadas en la ley, pero puede mantener intacto este cuerpo sustantivo y manipular por pacto la disponibilidad y el alcance de los remedios contractuales que aseguran la efectividad del cumplimiento". ÁNGEL CARRASCO-PERERA, Derecho de contratos, 66 (2a ed., Aranzadi, Pamplona, 2017).

6 A este particular nos referiremos más abajo.

7 Cfr., JORGE LÓPEZ-SANTA MARÍA \& FABIÁN ELORRIAGA DE BONIS, Los contratos, Parte general, $275-276$ (6 $\mathrm{ed}$., Thomson Reuters, Santiago, 2017). Los autores expresan: "El principio de la libertad contractual, a diferencia de en nuestro país, en que en ninguna norma lo consagra directa y formalmente (...)”. Nuestra Corte Suprema, pese a la ausencia de una norma general que reconozca el principio, en sentencia de 22 de enero de 2008, declara: "la regla general en el derecho es la libertad de las partes para celebrar cualquier contrato, porque en general todo objeto es lícito, pero, por razones de moralidad o de conveniencia pública la ley prohíbe la celebración de ciertos contratos (...)".Chile, Corte Suprema, 22 de enero de 2008, Rol 3247-2006. Cita en línea: LegalPublishing 38181. Y la misma Corte Suprema, en sentencia de 17 de marzo de 2009, aclara: "ha de tenerse presente que dicho precepto (artículo 1545 del Código Civil) sienta el principio por el cual se le da realce a la autonomía de la voluntad en cuya virtud opera la libertad de que gozan los particulares para pactar los contratos que plazcan y de determinar su contenido, efectos y duración”. Chile, Corte Suprema, 17 de marzo de 2009, Rol 6914-2007. Cita en línea: LegalPublishing 41820.

8 MARIO E. CLEMENTE-MEORO, La facultad de resolver los contratos por incumplimiento, 424 (Editorial Tirant lo Blanch, Valencia, 1998).

9 CARLOS PIZARRO-WILSON, Cláusula resolutoria y pacto comisorio calificado. Tan lejos, tan cerca, en Estudios de Derecho Civil VIII, Jornadas Nacionales de Derecho Civil, Santa Cruz, 2012, 360 (CARMEN DOMÍNGUEZHIDALGO, JOEL GONZÁLEZ-CASTILLO, MARCELO BARRIENTOS-ZAMORANO \& JUAN LUIS GOLDENBERG-SERRANO, coords., Thomson Reuters, Santiago, 2013).

10 BEATRIZ GREGORACI, Cláusula resolutoria y control del incumplimiento, 33 (Derecho Privado, Agencia Estatal Boletín Oficial del Estado, BOE, Madrid, 2015). En el mismo sentido, JESÚS ALFARO ÁGUILA-REAL, Las condiciones generales de la contratación, 87-89 (Civitas, Madrid, 1991).

11 MARIO E. CLEMENTE-MEORO, La facultad de resolver los contratos por incumplimiento, 39, nota 14 (1998). ENRIQUE BARROS-BOURIE, Finalidad y alcance de las acciones y los remedios contractuales, en Estudios de derecho 
civil III, Jornadas Nacionales de Derecho Civil, Valparaiso 2007, 403-428, 403 (ALEJANDRO GUZMÁN-BRITO, ed., Valparaíso, LexisNexis, 2007). En esta dirección, PIETRO PERLINGIERI aclara: “La situación subjetiva activa que definimos como derecho potestativo atribuye a su titular el poder de provocar unilateralmente un hecho jurídico que comporta consecuencias desfavorables para otro sujeto. Por esta razón, el derecho potestativo también puede denominarse poder formativo: su titular puede constituir, modificar o extinguir una situación subjetiva, unilateralmente, a pesar de que eso signifique la invasión de la esfera jurídica de otro sujeto que, además, no puede evitar tal acción, es decir, debe someterse al ejercicio del poder. El derecho potestativo se ejercita con una manifestación unilateral de voluntad, aunque, según algunos autores, en ciertos casos, para realizar el resultado favorable al titular, hace falta, además de la manifestación unilateral de voluntad, la sentencia de un juez". PIETRO PERLINGIERI, El derecho civil en la legalidad constitucional según el sistema italo-comunitario de las fuentes, 621 ( 3 a ed., AGUSTÍN LUNA-SERRANO \& CARLOS MALUQUER DE MOTES Y BERNET, trads., Dykinson, Madrid, 2008).

12 CARLOS PIZARRO-WILSON, Cláusula resolutoria y pacto comisorio calificado. Tan lejos, tan cerca, , 362 (2013).

13 En este sentido, el artículo 26 de la Convención de las Naciones Unidas sobre los Contratos de Compraventa Internacional de Mercaderías o Convención de Viena señala que "la declaración de resolución del contrato surtirá efecto solo si se comunica a la otra parte". Por su parte, el artículo 7.3.2 (1) los Principios UNIDROIT sobre los Contratos Comerciales Internacionales prescribe que "el derecho de una parte a dar por terminado el contrato se ejercitará mediante comunicación a la otra parte" (art. 9:303 Principles of European Contract Law, PECL).

14 INIIGO DE LA MAZA-GAZMURI \& ÁLVARO VIDAL-OLIVARES, El contenido: una primera aproximación, en Los Principios Latinoamericanos de Derecho de los Contratos, Texto, presentación y contenidos fundamentales, 27-75, 68 (ÍNIIGO DE LA MAZA-GAZMURI, CARLOS PIZARRO-WILSON \& ÁLVARO VIDAL-OLIVARES, coords., ed., Derecho Privado, Agencia Estatal Boletín Oficial del Estado, BOE, Madrid, 2017).

15 Artículo 87. Carácter esencial del incumplimiento. Se entiende que el incumplimiento es esencial cuando: (a) Las partes así lo han acordado respecto de obligaciones determinadas o de supuestos específicos de incumplimiento. (b) Es doloso. (c) La conducta del deudor incumplidor hace perder razonablemente al acreedor la confianza en el cumplimiento posterior del contrato. (d) Prive sustancialmente al acreedor de aquello que podía esperar de acuerdo con lo que era previsible para las partes al tiempo de celebrarse el contrato. (e) El deudor no cumple dentro del plazo de subsanación del artículo 93.

16 ANDREA BOTTESELLE-MÁRDONES, El pacto comisorio como manifestación de la facultad resolutoria, 17 Revista Chilena de Derecho Privado, RChDP, 71-103, 93-98 (2011).

17 LUIS CLARO-SOLAR, Explicaciones de derecho civil chileno y comparado, vol. 5, De las obligaciones, 197 (Editorial Jurídica de Chile, Santiago, 1979). RENÉ ABELIUK-MANASEVICH, Las obligaciones, Tomo I, 422, 423 (3a ed., Thomson Reuters, Santiago, 2014). ARTURO ALESSANDRI-RODRÍGUEZ, De la compraventa y de la promesa de venta, Tomo II, 329, 458 (Editorial Jurídica de Chile, Santiago, 2003).

18 ARTURO ALESSANDRI-RODRÍGUEZ, De la compraventa y de la promesa de venta, Tomo II, 462 (Editorial Jurídica de Chile, Santiago, 2003). RENÉ RAMOS-PAZOS, De las obligaciones, 181-182 (3a ed, LexisNexis, Santiago, 2008).

19 Cfr., CARLOS PIZARRO-WILSON, Cláusula resolutoria y pacto comisorio calificado. Tan lejos, tan cerca, , 358-359 (2013).

20 CARLOS PIZARRO-WILSON, Las cláusulas resolutorias en el derecho civil chileno, III Cuadernos de Análisis Jurídico, Colección de Derecho Privado, , 256-257 (2006).

21 Hemos de advertir que en el nuevo orden la cláusula resolutoria implícita también opera extrajudicialmente y requiere de un incumplimiento esencial, una comunicación y emplazamiento para que cumpla, salvo incumplimiento esencial o conducta rebelde del deudor. En este último caso, bastará la comunicación (art. 1087).

22 Énfasis agregado.

23 ELSA MANRIQUE, El pacto comisorio en el Código Civil y Comercial de la Nación, 7 Revista Científica Semestral In Iure, Ciencias Jurídicas y Notariales, 1, 25-43 (2017). El nuevo código regula la cláusula resolutoria tácita y la cláusula resolutoria expresa en el capítulo 13, Extinción, modificación y adecuación del contrato. Tal como afirma MANRIQUE: "Estos artículos $(1087,1088$ y 1089) establecen los caminos a seguir por el acreedor de una prestación determinada en una obligación contractual, ante el incumplimiento de la otra parte, precisándose el sistema de la resolución como manera de concluir relaciones que, al haberse tornado ineficiente en su funcionalidad, producen la ineficacia del contrato". ELSA MANRIQUE, El pacto comisorio en el Código Civil y Comercial de la Nación..., 25-43, 28 (2017). Para un comentario del artículo 1087: http://universojus.com/ccc-comentado-infojus/introduccion-art-1087

24 Énfasis agregado. "Los contratantes pueden acordar expresamente que el contrato se resuelva en el caso que una obligación determinada no se cumpla conforme con lo convenido. En este caso, la resolución se verifica ipso jure cuando la parte interesada declara a la otra que quiere ejercer la cláusula resolutoria".

25 INIGO DE LA MAZA-GAZMURI \& ÁLVARO VIDAL-OLIVARES, El contenido: una primera aproximación, en Los Principios Latinoamericanos de Derecho de los Contratos, Texto, presentación y contenidos fundamentales, 27-75, 69 (DE LA MAZA-GAZMURI, ÍNIGO; PIZARRO-WILSON, CARLOS \& VIDAL-OLIVARES, ÁLVARO, coord., 
ed., Los Principios Latinoamericanos de Derecho de los Contratos, Texto, presentación y contenidos fundamentales (Derecho Privado, Agencia Estatal Boletín Oficial del Estado, BOE, Madrid, 2018). Disponible en: https://www.boe.es/publica ciones/biblioteca_juridica/abrir_pdf.php?id=PUB-PR-2017-44.

26 ANDREA BOTTESELLE-MÁRDONES, El pacto comisorio como manifestación de la facultad resolutoria, 17 Revista Chilena de Derecho Privado, RChDP, 71-103, 96-98 (2011).

27 Contrastar con MARÍA LUISA PALAZÓN-GARRIDO, Los remedios frente al incumplimiento en el Derecho comparado, 144-145 (Cizur Menor, Editorial Aranzadi, Pamplona, Navarra, 2014). ÁLVARO VIDAL-OLIVARES, La noción de incumplimiento esencial en el Código Civil, XXXII Revista de Derecho de la PUCV, Revista de Derecho de la Pontificia Universidad Católica de Valparaíso, 221-258, 226-232 (2009).

28 Sobre la esencialidad, CLAUDIA MEJÍAS-ALONZO, El incumplimiento que faculta a resolver el contrato a la luz de las disposiciones del Código Civil, VII Cuadernos de Análisis Jurídico, Colección Derecho Privado, Incumplimiento contractual. Nuevas perspectivas, 171-212, 182 ss. (ÍNIGO DE LA MAZA-GAZMURI, coord., Ediciones Universidad Diego Portales, Santiago, 2011). DANIEL PEÑAILILLO-ARÉVALO, Obligaciones. Teoria general y clasificaciones. La resolución por incumplimiento, 409 (Editorial Jurídica de Chile, Santiago, 2003). ÁLVARO VIDAL-OLIVARES, La noción de incumplimiento esencial en el Código Civil..., 221-258, 230 ss. (2009).

29 No descartamos aquellas cláusulas que provocan la resolución automática del contrato respecto de cuya eficacia nos referiremos al tratar los problemas de eficacia de la cláusula resolutoria. Para PIZARRO-WILSON, lo propio de la cláusula resolutoria es que no opere de pleno derecho; si es el caso, en su opinión, se estaría ante un pacto comisorio calificado al que le es inherente la resolución de pleno derecho, bastando el incumplimiento para entender que se ha verificado la resolución. CARLOS PIZARRO-WILSON, Cláusula resolutoria y pacto comisorio calificado. Tan lejos, tan cerca, 363 (2013).

30 La resolución en cuanto derecho potestativo, contrastar con A\#LVARO VIDAL-OLIVARES, El incumplimiento de obligaciones con objeto fungible y los remedios del acreedor afectado. Un intento de relectura de las disposiciones del Código Civil sobre incumplimiento, en El Código Civil de Chile (1855-2005), 495-551, 516 (ALEJANDRO GUZMÁNBRITO, ed., LexisNexis, Santiago, 2007). CLAUDIA MEJÍAS-ALONZO \& GONZALO SEVERIN-FUSTER, La justificación funcional del pacto comisorio en la compraventa, XXX Revista de Derecho (Valdivia), 2, 87-109, 105-106 (2017).

31 Como afirma GREGORACI, los argumentos a favor de las cláusulas resolutorias son dos: a) la libertad contractual; y b) el carácter dispositivo de la disposición del artículo 1124 CC, equivalente al chileno 1489. BEATRIZ GREGORACI, Cláusula resolutoria y control del incumplimiento, 33 (2015).

32 Chile, Corte Suprema, 27 de septiembre de 2016, Rol 17061-2016. Disponible también en: http://www.pjud.cl.

33 Otro podría ser el caso de una cláusula resolutoria que, conforme al art. 16, letra g) de la Ley 19.496, sea calificada judicialmente como abusiva. El precepto reza como sigue: "No producirán efecto alguno en los contratos de adhesión las cláusulas o estipulaciones que: En contra de las exigencias de la buena fe, atendiendo para estos efectos a parámetros objetivos, causen en perjuicio del consumidor, un desequilibrio importante en los derechos y obligaciones que para las partes se deriven del contrato. Para ello se atenderá a la finalidad del contrato y a las disposiciones especiales o generales que lo rigen. Se presumirá que dichas cláusulas se encuentran ajustadas a exigencias de la buena fe, si los contratos a que pertenecen han sido revisados y autorizados por un órgano administrativo en ejecución de sus facultades legales". Ver ÍNIGO DE LA MAZA-GAZMURI, El control de las cláusulas abusivas y la letra g, 3 Revista Chilena de Derecho Privado, Fernando Fueyo Laneri, 35-68 (2004).

34 Chile, Corte de Apelaciones de Santiago, 6 de noviembre de 2015, Rol 8276-2015. Cita en línea: CL/JUR/6741/2015.

35 Chile, Corte Suprema, 11 de mayo de 2016, Rol 4804-2015. Cita en línea: CL/JUR/3090/2016.

36 La interpretación se ha dado de manera consistente entre las Cortes de Apelaciones. Entre ellas, Corte de Apelaciones de Chillán, 11 de julio de 2008, Rol 128-2005. Cita en línea: CL/JUR/7792/2008. Chile, Corte de Apelaciones de Concepción, 23 de noviembre de 2009, Rol 584-2009. Cita en línea: CL/JUR/3868/2009. Chile, Corte de Apelaciones de Concepción, 20 de octubre de 2014, Rol 345-2014. Cita en línea: CL/JUR/7627/2014. Chile, Corte de Apelaciones de Concepción, 16 de noviembre de 2005, Rol 3461-2005. Cita en línea: CL/JUR/1740/2005. Chile, Corte de Apelaciones de Concepción, 13 de octubre de 2005, Rol 3130-2005. Cita en línea: CL/JUR/5607/2005. Chile, Corte de Apelaciones de Concepción, 9 de julio de 2003, Rol 347-2003. Cita en línea: CL/JUR/2481/2003.

37 Chile, Corte de Apelaciones de Santiago, 4 de junio de 2010, Rol 5484-2009. Cita en línea: CL/JUR/3135/2010.

38 Chile, Corte de Apelaciones de Santiago, 3 de junio de 2014, Rol 8281-2013. Cita en línea: CL/JUR/2871/2014.

39 Chile, Corte de Apelaciones de Concepción, 18 de agosto de 2016, Rol 159-2016.

40 En una antigua sentencia de la Corte Suprema, esta señaló que en cambio, el pacto comisorio calificado que las partes introdujeron en su contrato de arrendamiento comparte la naturaleza jurídica de la condición resolutoria ordinaria y por consiguiente, su cumplimiento — en la especie, la falta de pago de las rentas - produce ipso jure la extinción del arrendamiento, sin que sea menester una declaración judicial, razón por la cual el arrendatario carece de facultad para hacer subsistir el contrato consignando las rentas que en su oportunidad dejó de pagar; al respecto, cabe consignar que 
lo dispuesto en el artículo 1879 del Código Civil resulta inaplicable en la especie pues dicha norma es excepcional para el contrato de compraventa, de lo que resulta improcedente extender sus efectos a otras especies de contratos bilaterales. Chile, Corte Suprema, 8 de agosto de 1996, Rol 33888-1996. Cita en línea: CL/JUR/621/1996. Chile, Corte de Apelaciones de Concepción, 4 de marzo de 2013, Rol 1502-2012. Cita en línea: CL/JUR/499/2013. Chile, Corte de Apelaciones de Talca, 23 de septiembre de 2015, Rol 1953-2015. Cita en línea: CL/JUR/5742/2015.

41 BEATRIZ GREGORACI, Cláusula resolutoria y control del incumplimiento, $52-53$ (2015).

42 CARLOS PIZARRO-WILSON, Cláusula resolutoria y pacto comisorio calificado. Tan lejos tan cerca..., 362 (2013).

43 CARLOS PIZARRO-WILSON, Cláusula resolutoria y pacto comisorio calificado. Tan lejos tan cerca..., 363 (2013).

44 CARLOS PIZARRO-WILSON, Cláusula resolutoria y pacto comisorio calificado. Tan lejos tan cerca..., 364 (2013).

45 Chile, Corte Suprema, 30 de diciembre de 2009, Rol 5817-2008. Cita en línea: 46989. Para un comentario crítico de esta sentencia, CARLOS PIZARRO-WILSON, Cláusula resolutoria y pacto comisorio calificado. Tan lejos tan cerca, 362 (2013).

46 CARLOS PEÑA-GONZÁLEZ, La resolución como ineficacia extrinseca, apunte docente, 10-11 (inédito).

47 RAFAEL ANTONIO VERDERA-SERVER, Cláusula resolutoria y retraso en la entrega de vivienda, Comentario a la Sentencia de 13 de noviembre de 2013, 95 Cuadernos Civitas de Jurisprudencia Civil, CCJC, 467-492, 482 (2014).

48 En contra: ÁNGEL FERNANDO PANTALEÓN-PRIETO, Las nuevas bases de la responsabilidad contractual, 4 Anuario de Derecho Civil, 1719-1745, 1733, nota 49 (1993): “(...) me parece indudable que, salvo en condiciones generales de la contratación, las partes puedan configurar como les venga en gana el incumplimiento resolutorio".

49 Chile, Corte Suprema, 27 de septiembre de 2016, Rol 17061-2016. Cita en línea: CL/JUR/6688/2016.

50 Sobre la especificidad de los supuestos de incumplimiento, CARLOS PIZARRO-WILSON, Cláusula resolutoria y pacto comisorio calificado. Tan lejos tan cerca, 361 (2013).

51 Chile, Corte de Apelaciones de Santiago, 3 de julio de 2008, Rol 5817-2008. Cita en línea: 468989.

52 Chile, Corte Suprema, 27 de mayo de 2014, Rol 3407-2013. Cita en línea: CL/JUR/2673/2014. Del mismo modo, en años anteriores, Chile, Corte Suprema, 23 de marzo de 2009, Rol 5817-2008.

53 Reconocen la buena fe como límite de la eficacia de la cláusula resolutoria, entre otros: VICENTE LUIS MONTESPENADÉS, Artículo 1124CC, en Comentarios al Código Civily Compilaciones Forales, Tomo XV, Volumen 1, Artículos 1.088 a 1.124, 1215-1306, 1215-1216 (MANUEL ALBALADEJO-GARCÍA, dir., Editoriales de Derecho Reunidas, Edersa, Madrid, 1989). RAFAEL ÁLVAREZ-VIGARAY, La resolución de los contratos bilaterales por incumplimiento, 113 (Comares, Granada, 2009). En contra: JOSÉ MARÍA MIQUEL-GONZÁLEZ, Comentarios a las normas de protección de los consumidores. Texto refundido (RDL 1/2007) y otras leyes y reglamentos vigentes en España y en la Unión Europea, 737 (SERGIO CÁMARA-LAPUENTE, dir., Editorial Constitución y Leyes, COLEX, Coruña, 2011). Este autor expresa: "Cuando se trata de cláusulas resolutorias negociadas, la buena fe no es criterio de control de su contenido, porque pesa ante todo la libertad contractual y la buena fe en ese contexto de cláusulas negociadas obliga ante todo a cumplir lo pactado".

54 LIS PAULA SAN MIGUEL-PRADERA, La resolución por incumplimiento en la propuesta para la modernización del derecho de obligaciones y contratos: ¿lo mejor es enemigo de lo bueno?, LXIV Anuario de Derecho Civil, ADC, IV, 1685-1724, 1688-1690, 1715 (2011).

55 CRISTIÁN GANDARILLAS-SERANI, Algunas consideraciones acerca del deber de mitigación o minimización del daño frente al incumplimiento contractual, en Estudios de Derecho Civil IV, 435 y 440-446 (CARLOS PIZARROWILSON, coord., LegalPublishing, Santiago, 2009). CARLOS PIZARRO-WILSON, Hacia un sistema de remedios al incumplimiento contractual, en Estudios de Derecho Civil III, Jornadas Nacionales de Derecho Civil, Valparaiso 2007, 395-402, 397 (ALEJANDRO GUZMA\#N-BRITO, ed., LegalPublishing, Santiago, 2008). ÁLVARO VIDALOLIVARES, La carga de mitigar las pérdidas del acreedor y su incidencia en el sistema de remedios por incumplimiento, en Estudios de Derecho Civil III, Jornadas Nacionales de Derecho Civil, Valparaiso 2007, 446-447 (ALEJANDRO GUZMÁN-BRITO, ed., LegalPublishing, Santiago, 2008).

56 Chile, Corte Suprema, 2 de junio de 2016, Rol 6528-2015. Cita en línea: CL/JUR/3640/2016. Chile, Corte Suprema, 27 de mayo de 2014, Rol 3407-2013. Cita en línea: CL/JUR/2673/2014. Chile, Corte Suprema, 10 de diciembre de 2012, Rol 3320-2012. Chile, Corte Suprema, 12 de enero 2012, Rol 2319-2011. Cita en línea: CL/JUR/309/2012.

57 Atendiendo a si la obligación incumplida es principal o accesoria, RENÉ ABELIUK-MANASEVICH, Las obligaciones, Tomo I, 344 ( $3^{\mathrm{a}}$ ed., Thomson Reuters, Santiago, 2014); si acaso la obligación que se incumple se identifica con la esencia de lo pactado, LUIS CLARO-SOLAR, Lecciones de derecho civil chileno y comparado, IX, Obligaciones II, 190-193 (Nascimento, Santiago, 1937). Y, en fin, considerando el impacto que el incumplimiento tiene en el interés del acreedor, AUGUSTO ELGUETA-ANGUITA, Resolución de contratos y excepción de pago, 37 (Editorial Jurídica de Chile, Santiago, 1981). DANIEL PEÑAILILLO-ARÉVALO, Obligaciones. Teoría general y clasificaciones. La resolución por incumplimiento, 393-395 (Editorial Jurídica de Chile, Santiago, 2003).

58 ÁLVARO VIDAL-OLIVARES, La noción de incumplimiento esencial en el Código Civil..., 221-258, 253-255 (2009). CLAUDIA MEJÍAS-ALONZO, El incumplimiento resolutorio en el Código Civil, 179, 197-198 (Abeledo Perrot, Legal 
Publishing, Santiago, 2011). CLAUDIA MEJÍAS-ALONZO, El incumplimiento que faculta a resolver el contrato a la luz de las disposiciones del Código Civil, VII Cuadernos de Análisis Jurídico, Colección Derecho Privado, Incumplimiento contractual. Nuevas perspectivas, 171-212 (ÍNIGO DE LA MAZA-GAZMURI, coord., Ediciones Universidad Diego Portales, Santiago, 2011).

59 En los Principios sobre Contratos Comerciales Internacionales, PCCI, 2016, de UNIDROIT, en su artículo 7.3.1, se lee: "b) el cumplimiento estricto de la obligación era esencial dentro del contrato". Los PLDC, por su parte, señalan en su artículo 87 que el incumplimiento será esencial cuando “(a) Las partes así lo han acordado respecto de obligaciones determinadas o de supuestos específicos de incumplimiento".

60 Chile, Corte de Apelaciones de Santiago, 29 de noviembre de 2007, Rol 3073-2003. Cita en línea: CL/JUR/3963/2007.

61 Chile, Corte de Apelaciones de Santiago, 3 de julio de 2008, Rol 761-2006.

62 Sobre la posibilidad de control de los incumplimientos resolutorios pactados por las partes, con una amplia cita de sentencias y doctrina española, BEATRIZ GREGORACI, Cláusula resolutoria y control del incumplimiento, 33-53 (2015).

63 A partir de lo resuelto por la Corte Suprema y de ciertas Cortes de Apelaciones en los últimos años, sería posible considerar que la incorporación de una cláusula resolutoria no impediría el ejercicio de la facultad resolutoria prevista en el artículo 1489, puesto que ha sostenido que el efecto de estas cláusulas no es la resolución de pleno derecho del contrato. Entre ellos, Chile, Corte Suprema, 21 de enero de 2013, Rol 5504-2011. Cita en línea: CL/JUR/131/2013. Chile, Corte Suprema, 9 de abril de 2007, Rol 5869-2005. Cita en línea: CL/JUR/5818/2007.

64 Chile, Corte Suprema, 9 de diciembre de 2008, Rol 5821-2007. Cita en línea: CL/JUR/6929/2008.

65 CARLOS PIZARRO-WILSON, Cláusula resolutoria y pacto comisorio calificado. Tan lejos tan cerca, 362 (2013).

66 ANTONIO MANUEL MORALES-MORENO, Incumplimiento del contrato y lucro cesante, 176 (Thomson Civitas, Pamplona, Navarra, 2010).

67 A modo de ejemplo, y para ilustrar lo expresado, solo basta con que consideremos la regla del artículo 1558 del Código Civil que, ante el silencio de las partes, se incorpora naturalmente al contrato. Según la disposición citada, si se prueba dolo o culpa grave del deudor, este queda privado de la protección que le confiere la regla de la previsibilidad como límite a la indemnización de daños y se abre paso el principio de la reparación integral. Lo mismo podemos predicar respecto de las cláusulas de exoneración o limitación de responsabilidad cuando el deudor incumple con dolo, cláusulas que adolecerían de objeto ilícito y serían nulas de nulidad absoluta.

* Artículo de investigación.

\section{Licencia Creative Commons CC BY 4.0}

Para citar este articulo / To cite this article: VIDAL-OLIVARES, ÁLVARO, La cláusula resolutoria como manifestación de la facultad de resolver el contrato. Problemas en torno a su eficacia en el Código Civil chileno, 138 Vniversitas (2019). https://doi.org/10.11144/Javeriana.vj138.crmf 